\title{
A simple method of equine limb force vector analysis and its potential applications
}

\author{
Sarah Jane Hobbs ${ }^{\text {Corresp.. }}{ }^{1}$, Mark A Robinson ${ }^{2}$, Hilary M Clayton ${ }^{3}$ \\ ${ }^{1}$ Centre for Applied Sport and Exercise Sciences, University of Central Lancashire, Preston, UK \\ 2 Research Institute for Sport and Exercise Sciences, Liverpool John Moores University, Liverpool, United Kingdom \\ 3 Department of Large Animal Clinical Sciences, Michigan State University, East Lansing, Michigan, United States \\ Corresponding Author: Sarah Jane Hobbs \\ Email address: sjhobbs1@uclan.ac.uk
}

Background. Ground reaction forces (GRF) measured during equine gait analysis are typically evaluated by analyzing discrete values obtained from continuous force-time data for the vertical, longitudinal and transverse GRF components. This paper describes a simple, temporo-spatial method of displaying and analyzing sagittal plane GRF vectors. In addition, the application of statistical parametric mapping (SPM) is introduced to analyse differences between contra-lateral fore and hindlimb force-time curves throughout the stance phase. The overall aim of the study was to demonstrate alternative methods of evaluating functional (a)symmetry within horses.

Methods. GRF and kinematic data were collected from 10 horses trotting over a series of 4 force plates $(120 \mathrm{~Hz})$. The kinematic data were used to determine clean hoof contacts. The stance phase of each hoof was determined using a $50 \mathrm{~N}$ threshold. Vertical and longitudinal GRF for each stance phase were plotted both as force-time curves and as force vector diagrams in which vectors originating at the centre of pressure on the force plate were drawn at intervals of $8.3 \mathrm{~ms}$ for the duration of stance. Visual evaluation was facilitated by overlay of the vector diagrams for different limbs. Summary vectors representing the magnitude (VecMag) and direction (VecAng) of the mean force over the entire stance phase were superimposed on the force vector diagram. Typical measurements extracted from the force-time curves (peak forces, impulses) were compared with VecMag and VecAng using partial correlation (controlling for speed). Paired samples t-tests (left $v$ right diagonal pair comparison and high $v$ low vertical force diagonal pair comparison) were performed on discrete and vector variables using traditional methods and Hotelling's $T^{2}$ tests on normalized stance phase data using SPM.

Results. Evidence from traditional statistical tests suggested that VecMag is more influenced by the vertical force and impulse, whereas VecAng is more influenced by the longitudinal force and impulse. When used to evaluate mean data from the group of ten sound horses, SPM did not identify differences between the left and right contralateral limb pairs or between limb pairs classified according to directional asymmetry. When evaluating a single horse, three periods were identified during which differences in the forces between the left and right forelimbs exceeded the critical threshold $(p<.01)$.

Discussion. Traditional statistical analysis of 2D GRF peak values, summary vector variables and visual evaluation of force vector diagrams gave harmonious results and both methods identified the same interlimb asymmetries. As alpha was more tightly controlled using SPM, significance was only found in the individual horse although $\mathrm{T}^{2}$ plots followed the same trends as discrete analysis for the group.

Conclusions. The techniques of force vector analysis and SPM hold promise for investigations of sidedness and asymmetry in horses. 
1 A simple method of equine limb force vector analysis and its

2 potential applications

3 Sarah Jane Hobbs ${ }^{1}$, Mark A. Robinson ${ }^{2}$ and Hilary M. Clayton ${ }^{3}$

$4 \quad{ }^{1}$ Centre for Applied Sport and Exercise Sciences, University of Central Lancashire, Preston, UK.

$5{ }^{2}$ Research Institute for Sport and Exercise Sciences, Liverpool John Moores University,

6 Liverpool, UK.

$7 \quad{ }^{3}$ Department of Large Animal Clinical Sciences, Michigan State University, East Lansing, MI, 8 USA.

9 Corresponding Author:

10 Sarah Hobbs ${ }^{1}$,

11 E-mail: sjhobbs1@uclan.ac.uk 


\section{Abstract}

13 Background. Ground reaction forces (GRF) measured during equine gait analysis are typically

14 evaluated by analyzing discrete values obtained from continuous force-time data for the vertical,

15 longitudinal and transverse GRF components. This paper describes a simple, temporo-spatial

16 method of displaying and analyzing sagittal plane GRF vectors. In addition, the application of

17 statistical parametric mapping (SPM) is introduced to analyse differences between contra-lateral

18 fore and hindlimb force-time curves throughout the stance phase. The overall aim of the study

19 was to demonstrate alternative methods of evaluating functional (a)symmetry within horses.

20 Methods. GRF and kinematic data were collected from 10 horses trotting over a series of 4 force

21 plates $(120 \mathrm{~Hz})$. The kinematic data were used to determine clean hoof contacts. The stance phase

22 of each hoof was determined using a $50 \mathrm{~N}$ threshold. Vertical and longitudinal GRF for each

23 stance phase were plotted both as force-time curves and as force vector diagrams in which

24 vectors originating at the centre of pressure on the force plate were drawn at intervals of $8.3 \mathrm{~ms}$

25 for the duration of stance. Visual evaluation was facilitated by overlay of the vector diagrams for

26 different limbs. Summary vectors representing the magnitude (VecMag) and direction (VecAng)

27 of the mean force over the entire stance phase were superimposed on the force vector diagram.

28 Typical measurements extracted from the force-time curves (peak forces, impulses) were

29 compared with VecMag and VecAng using partial correlation (controlling for speed). Paired

30 samples t-tests (left $\mathrm{v}$ right diagonal pair comparison and high $\mathrm{v}$ low vertical force diagonal pair

31 comparison) were performed on discrete and vector variables using traditional methods and

32 Hotelling's T2 tests on normalized stance phase data using SPM. 
33 Results. Evidence from traditional statistical tests suggested that VecMag is more influenced by

34 the vertical force and impulse, whereas VecAng is more influenced by the longitudinal force and

35 impulse. When used to evaluate mean data from the group of ten sound horses, SPM did not

36 identify differences between the left and right contralateral limb pairs or between limb pairs

37 classified according to directional asymmetry. When evaluating a single horse, three periods were

38 identified during which differences in the forces between the left and right forelimbs exceeded

39 the critical threshold $(\mathrm{p}<.01)$.

40 Discussion. Traditional statistical analysis of 2D GRF peak values, summary vector variables and

41 visual evaluation of force vector diagrams gave harmonious results and both methods identified

42 the same inter-limb asymmetries. As alpha was more tightly controlled using SPM, significance

43 was only found in the individual horse although T2 plots followed the same trends as discrete

44 analysis for the group.

45 Conclusions. The techniques of force vector analysis and SPM hold promise for investigations of

46 sidedness and asymmetry in horses.

\section{Introduction}

48 Locomotion results from the application of ground reaction forces (GRF) in accordance with the

49 laws of motion formulated by Sir Isaac Newton. Forces are invisible but they can be measured

50 using multi-dimensional force plates or force shoes. Typically, the 3D force is resolved into

51 components according to the adopted coordinate system that are displayed as force-time graphs.

52 The forces are analyzed by extracting peak values and their times of occurrence, and by 
53 calculating the associated impulses. Statistical analyses are then used to detect differences

54 between horses, limbs or experimental conditions.

55 This approach has facilitated the description of normative GRF values at different gaits (Clayton,

56 Schamhardt and Hobbs, 2017; Khumsap et al., 2001; Merkens et al., 1986, 1993a, 1993b) and

57 speeds (Dutto et al., 2004; Hobbs, Bertram and Clayton, 2016). Changes in the typical force

58 patterns and values have been reported in association with lameness (e.g. Back et al., 2007;

59 Ishihara et al., 2005; Khumsap et al., 2003; Merkens et al., 1988; McLauchlan et al., 1996;

60 Weishaupt et al., 2004a, 2004b, 2006; Weishaupt, 2008), farriery modifications (e.g. Riemersma

61 et al., 1996), local anesthesia (Bidwell et al., 2004), asymmetry (Wiggers et al., 2015) and

62 training (Hobbs, Bertram and Clayton, 2016; Clayton and Hobbs, 2017). Left-right asymmetries

63 in peak vertical GRF are the most specific and sensitive GRF variable for detecting lameness

64 (Ishihara et al., 2005) and have been applied in establishing asymmetry thresholds for lameness

65 diagnosis (Weishaupt, 2008).

66 Peak GRF values represent only a small part of the force-time signal and analytic methods based

67 solely on evaluating GRF peaks ignore a large amount of information. A more detailed examination of the GRF curves has been explored using six characteristic time points, five corresponding longitudinal GRF magnitudes and peak vertical GRF (Dow et al., 1991; Williams et al., 1999). Both studies identified subtle modifications in GRF patterns due to injury or disease and advocated this approach when studying asymmetry. The limitations of using this approach are that a larger number of discrete variables need to be extracted from the force-time curves and as a consequence data analysis and interpretation are also more complicated. In this paper we

74 describe techniques for analyzing continuous force-time data that include all the available

75 information, but with fewer variables and with useful methods to aid visual interpretation. 
76 Application of these techniques may assist in expanding current knowledge of key functional

77 adaptations and in detecting compensatory mechanisms associated with asymmetrical movement 78 patterns.

79 Visualization of GRF data is based on displaying the force vectors as a series of arrows with the

80 length of each arrow scaled to the magnitude of the force, the orientation indicating the direction

81 in which the force acts, and the origin at the point of force application. In horses, this technique

82 lends itself to displaying the magnitude and direction of the 2D GRFs of one or more limbs in a

83 single diagram, so that differences between horses, limbs and conditions are more easily

84 appreciated. A similar method, known as Pedotti diagrams or Butterfly diagrams, has been used

85 to study 2D GRFs in human locomotion (Pedotti, 1977; Khondadadeh, Whittle and Bremble,

86 1986; Kambhampati, 2007; Berki et al., 2015).

87 Statistical interpretation of continuous GRF data may also provide an insight into functional

88 differences occurring outside of typical discrete time points (e.g. peak values) within the stance

89 phase (Pataky, Robinson and Vanrenterghem, 2013). Here, we present two methods for analyzing

90 the GRF data. Firstly, summary vector variables that encapsulate the effect of the GRF are

91 derived from the sagittal plane vector diagrams for the diagonal limb pairs of trotting horses.

92 These summary vector variables are analysed using traditional statistical methods. Secondly, the

93 continuous vertical and longitudinal GRF vector is explored using statistical parametric mapping

94 (SPM) (Penny et al., 2007; Pataky, Robinson and Vanrenterghem, 2013), which can objectively

95 identify significantly different regions between two GRF profiles. The analysis in this study is

96 restricted to $2 \mathrm{D}$ as the sagittal plane is considered to be the primary plane of motion during

97 trotting (Merkens and Schamhardt, 1994), large between and within horse variability have 
98 questioned the value of medio-lateral GRF data (Ishihara et al., 2005) and sagittal plane GRF data

99 is still most commonly reported in horses (including Wiggers et al., 2015).

100 The aims of the study are, therefore, firstly to demonstrate the utility of vector diagrams as visual

101 aids that illustrate functional (a)symmetry within horses, secondly to compare the statistical

102 results of traditional discrete GRF variables against a) summary vector variables and b)

103 continuous data using SPM analysis in relation to symmetry/asymmetry. Based on the results of

104 Williams et al. (1999) it was hypothesized that subtle asymmetries in subjectively sound horses

105 may be detectable using the proposed alternative methods of analysis. As summary vector

106 variables provide metric values that may be used to quantify asymmetry, a third aim was to

107 explore relationships between traditional discrete variables and summary vector variables. It was

108 hypothesized that summary vector variables would be correlated with traditional vector variables, 109 as both sets of variables were obtained from the same GRF data.

110 Methodology

111 This study was performed with approval from the institutional animal care and use committee 112 under protocol number 02/08-020-00 (Michigan State University, USA).

113 For the development of the force vector analysis technique, GRF data were collected from 10

114 horses $($ mean $\pm \mathrm{SD}$, mass $=463 \pm 38 \mathrm{~kg}$; height $=1.49 \pm 0.07 \mathrm{~m})$. The horses were assessed

115 subjectively as being free from lameness (Grade 0/5 on the American Association of Equine

116 Pracitioners lameness scale) (American Association of Equine Pracitioners, 2017) by an

117 experienced veterinarian. 
Data Collection

119 The 10 horses trotted in hand over a series of four synchronized force plates; the first and last

120 plates measured 60x120 cm (FP60120, Bertec Corp., Columbus, OH) and the middle two

121 measured 60x90 cm (FP6090, Bertec Corp., Columbus, OH). The rubberized runway was $40 \mathrm{~m}$ in

122 length with the force plates embedded in the middle part of the runway and operating at $960 \mathrm{~Hz}$.

123 Retroreflective markers attached to the trunk and mid-lateral wall of each hoof were tracked at

$124120 \mathrm{~Hz}$ using 10 infra-red cameras (Eagle cameras, Motion Analysis Corp.) and motion analysis

125 software (Cortex 1.1.4.368, Motion Analysis Corp.). All horses were familiarized with the

126 research environment prior to data collection. Data were collected with the horses trotting at a

127 consistent speed within and between trials until 3 valid trials had been saved for each horse

128 (speed was derived from the trunk marker). Relative speed was calculated by dividing speed (ms

$129^{1}$ ) by the square root of (standing height $(\mathrm{m})$ multiplied by acceleration due to gravity $\left(\mathrm{ms}^{-2}\right)$ )

130 (Bertram et al., 2000). A valid trial consisted of a complete stride that included consecutive clean

131 hits on the force platform from all four limbs. Each stance phase was detected initially using the

132 kinematic data to ensure that only one hoof contacted the force platform, it was completely on the

133 force platform, and was not close to the edge. The stance phases were then identified for each

134 limb using a threshold of $50 \mathrm{~N}$ for footstrike and lift off.

135 Asymmetries in conformation, musculoskeletal adaptations and previous injuries/pathologies (for 136 example Pearce et al., 2005; Stubbs et al., 2010; Wiggers et al., 2015) amongst other factors may

137 lead to individual gait adaptations that are masked in a group analysis, due to between horse

138 variability. As such, one of the horses (horse 10, mass: $425 \mathrm{~kg}$; height: $1.45 \mathrm{~m}$ ) was used to

139 explore intra-individual gait asymmetries. In this horse, data collection was continued until 8

140 valid trials had been collected. 
141 Force Vector Analysis (FVA)

142 All analyses were conducted using sagittal plane data. To create vector diagrams and summary

143 vector variables GRF data were down-sampled to $120 \mathrm{~Hz}$ from the original capture rate of 960

$144 \mathrm{~Hz}$ and normalized to horse mass. The GRF vectors of each limb were plotted as a vector

145 diagram in Excel (Microsoft Limited, Reading, Berks, UK). Each vector had its origin at its

146 centre of pressure on the force plate (that is the point of application of the GRF vector), with

147 magnitude and orientation scaled to the sagittal plane GRF, as described by Kambhampati (2007).

148 At a sampling rate of $120 \mathrm{~Hz}$, vectors were created at intervals of $8.3 \mathrm{~ms}$ for the duration of the

149 stance phase. The vector diagram was completed by the addition of a scaled vertical reference

150 line passing through the middle of the hoof from heel to toe (Figure 1).

151 Quantitative metrics of typical GRF variables were extracted for the group of 10 sound horses

152 based on 3 trotting trials ( 1 stance phase for each limb per trial, per horse) and for horse 10

153 individually based on 8 trotting trials ( 1 stance phase for each limb for per trial) (Back et al.,

154 2007; Ishihara et al., 2005; Khumsap et al., 2003; Merkens et al., 1988; McLauchlin et al., 1996;

155 Weishaupt et al., 2004a, 2004b, 2006; Weishaupt, 2008). The variables included peak force

156 values, time of force peaks, and impulses for the vertical, longitudinal braking and longitudinal

157 propulsive GRF in each limb. The shape of the vector diagram was represented by the vector

158 envelope connecting the tips of the vectors that form the vector diagram (Figure 1). A summary

159 vector representing the magnitude and direction of the mean GRF over the entire stance phase

160 was superimposed on the vector diagram (Figure 1) and two summary variables were derived; the

161 vector magnitude (VecMag) was calculated by vector summation of the individual vectors

162 divided by the number of samples contributing to the value. The angle of the summary vector

163 (VecAng) was determined from the components of the vector magnitude using trigonometry and

164 expressed relative to the vertical with positive values being directed cranially. Typical GRF 
165 variables, and summary vector magnitudes and angles for the fore and hind limbs were tabulated, 166 together with mean speed per step.

167 Coefficient of variation(COV) of typical GRF variables (peak forces, impulses) and VecMag 168 were calculated and compared using a mean value from the 3 stance phases for each limb per 169 horse for the group analysis and 8 stance phases for each limb for the individual horse analysis. 170 Simple bootstrapping was used on variables that were not normally distributed. Paired samples t171 tests (left v right) were performed to compare the values of the discrete and summary vector 172 variables between left and right forelimbs and left and right hind limbs for the group and for 173 Horse 10 individually. Additional analysis of the group data was performed with the diagonal 174 pairs of each horse re-classified by the forelimb mean peak vertical GRF to compare between 175 limbs based on directional asymmetric bias in individual horses (Starke et al., 2013). Discrete 176 variables and summary vector variables of the higher forelimb GRF diagonal pair (high) versus 177 the lower (low) forelimb GRF diagonal pair were compared using paired samples t-tests (high v 178 low). Significance was identified at $\mathrm{p}<.05$. Relationships between GRF variables and vector 179 variables were explored for the group using partial correlation with relative speed as a covariate.

180 Statistical Parametric Mapping (SPM) Analysis

181 For SPM analysis of GRF data, values of the vertical and longitudinal GRF components (mean of 1823 stance phases for each limb and each horse for the group analysis, 8 stance phases for each limb 183 for the individual horse analysis) were normalized to horse mass $(\mathrm{N} / \mathrm{kg})$ and stance duration (101 184 points). For the group analysis, these normalized stance phase values were assembled into $18510 * 101 * 2$ vector fields (10 horses, 101 data points per stance phase, two dimensions per data 186 point) for each limb. For the individual horse analysis, these normalized stance phase values were 187 assembled into $8 * 101 * 2$ vector fields ( 8 stance phases, 101 data points per stance phase, two 
188 dimensions per data point) for each limb. The open-source spm1d package (v. M.0.4.1, Pataky, 189 2012) was used to conduct the SPM analysis in Matlab (R2017a, The Mathworks Inc., Natick, 190 MA, USA). Hotelling's $T^{2}$ tests, the vector-field equivalent of the paired-samples t-test, were used 191 to compare stance phases of the left and right forelimbs and hind limbs (left v right) using vector 192 GRFs (i.e. vertical and longitudinal continuous data together) for the group of horses and for 193 horse 10 individually (Pataky, Robinson and Vanrenterghem, 2013). SPM analysis utilizes

194 Random Field Theory to determine the critical threshold at which only alpha \% of equivalently 195 smooth random data would cross. This ensures a tight control of the type I error rate (Pataky et al. 196 2016). Any crossings of the critical threshold therefore by definition have a probability of 197 occurrence less than alpha \%. Where significant differences were identified, a post-hoc paired 198 SPM t-test was conducted on the two individual GRF components.

199 Following the initial analysis, the vector fields for each diagonal pair of each horse in the group 200 were then re-classified according to mean peak vertical GRF and compared (high v low) using 201 SPM.

202 Visualization

203 Qualitative vector diagrams were prepared from an example horse in the group together with 204 typical graphical and force diagrams and stick images. Vector diagrams were initially organized 205 by diagonal limb pairs. Subsequently, diagrams for contralateral limbs were overlaid to facilitate 206 detection of functional differences between left and right limbs.

\section{Results}


208 For the group of ten horses, mean relative speeds for the two diagonals were: Left Fore Right

209 Hind (LFRH): $0.83 \pm 0.10 \mathrm{~m} / \mathrm{s}$, Right Fore Left Hind (RFLH): $0.83 \pm 0.09 \mathrm{~m} / \mathrm{s}(\mathrm{mean} \pm$ s.d.).

210 Table 1 reports directional asymmetry bias information for the group of horses. These data were

211 used to re-classify the horses into high and low diagonal pairs. Six horses had higher GRFs in the

212 left forelimb, so in the reclassification according to mean peak vertical GRF in the forelimb, GRF

213 data from four horses moved to the opposite diagonal compared with the left-right classification.

214 Typical GRF variables and vector summary variables for left and right diagonal pairs and for high

215 and low diagonal pairs for the group are shown in Tables 2 and 3 respectively. COV for the group

216 were lower for vertical GRF components and higher for longitudinal GRF components, except

217 for time to peak propulsive force which had a COV similar to the vertical GRF components. For

218 the summary vectors, variability in VecMag was low (below 10\% COV), but the range of

219 VecAng, particularly in the hindlimbs, was relatively large compared to the mean values, which

220 reflects the variability in the longitudinal GRF. Significant differences $(p<.05)$ in left compared to

221 right limbs for the group were only found in the forelimbs for peak braking force (left $>$ right),

222 braking impulse (left $>$ right) and vector angle (left more caudally directed than right) (Table 2). In

223 comparison, significant differences $(\mathrm{p}<.05)$ for high diagonal compared to low diagonal were

224 only found in the forelimbs for peak vertical GRF (high $>$ low), vertical impulse (high $>$ low) and

225 vector magnitude (high $>$ low), see Table 3.

226 Figure 1 indicates a typical force vector diagram in which the braking vectors point caudally and 227 delineate the caudal edge of the vector envelope, whereas propulsive vectors point cranially and 228 delineate the cranial edge of the envelope. Figure 2 shows serial stick figures of a trotting horse 229 (Figure 2A) with the corresponding vertical (Figure 2B) and longitudinal (Figure 2C) force-time 230 graphs and force vector diagrams (Figure 2D) including the summary vectors for the LFRH (left) 
231 and RFLH (right) diagonals. The vector diagrams have a preponderance of braking vectors in the

232 forelimbs and propulsive vectors in the hind limbs, and the sign of VecAng is negative in the

233 forelimbs and positive in the hind limbs. The forelimbs typically have a higher peak vertical GRF

234 than the hind limbs resulting in a higher vector envelope and a larger value for VecMag.

235 Results for SPM of continuous stance phase GRF data for the group of horses are shown in

236 Figure 3 (left v right) and Figure 4 (high v low) in which the horizontal dashed line indicates the

237 critical threshold above which left and right values are significantly different. There were no

238 significant differences $(\mathrm{p}>.05)$ in the fore or hind limbs for the analysis combining vertical and

239 longitudinal GRF for either left $\mathrm{v}$ right or high $\mathrm{v}$ low. The $\mathrm{T}^{2}$ value for the forelimbs is a little

240 higher between about 20-70\% stance for left $\mathrm{v}$ right, which encompasses the time when both

241 vertical and longitudinal GRF components reach their peak values (Figure 3). In contrast, the $\mathrm{T}^{2}$

242 values for the forelimbs for high versus low show a smaller increase over a shorter period of time

243 in the middle of the stance phase, around the time of vertical GRF peak values (Figure 4).

244 Results for GRF variables in the individual horse (horse 10) are reported in Table 4. Mean

245 relative speeds for the two diagonals were: LFRH: $0.74 \pm 0.02 \mathrm{~m} / \mathrm{s}, \mathrm{RFLH}: 0.74 \pm 0.02 \mathrm{~m} / \mathrm{s}$.

246 Within the individual horse, the COV for different variables were similar to those of the group. A

247 number of variables differed significantly between contralateral limbs. In the forelimbs these

248 included peak vertical force which was $2.7 \%$ greater in the right forelimb compared to the left,

249 VecMag (right $>$ left) and VecAng (right more caudally directed than left). In the hind limbs, peak

250 vertical GRF, vertical impulse, and peak longitudinal propulsive GRF were higher in the left hind

251 limb. 
252 Results of SPM of stance phase GRF data for horse 10 (Figure 5) showed significant differences

253 between GRF vectors for the left and right forelimbs $(\mathrm{p}<0.05)$ but not for the hind limbs. In the

254 forelimbs three clusters of data points exceeded the critical threshold at $14.8-16.2 \%, 43.0-45.9 \%$

255 and $83.7-85.1 \%$ stance (all $\mathrm{p}<.001$ ). Post-hoc analysis of the individual GRF components

256 revealed that the first two peaks in the $2 \mathrm{D}$ vector result are primarily influenced by the vertical

257 component whereas the third peak is likely a combination, but more by the longitudinal

258 component.

259 Superimposition of the vector diagrams for the contralateral limbs (Figure 6) show differences in 260 function of the left and right limbs during one stride in horse 10. The right forelimb envelope is

261 taller (corresponding with the second period of SPM significance), but not noticeably wider than

262 that of the left forelimb. The shape of the envelope and density of the vectors indicate that the

263 right forelimb produces more braking GRF in early stance whereas the left forelimb produces

264 more propulsion in late stance, which coincide with the first and third clusters of data points that

265 reached significance in the SPM plot (Figure 5). The left hind limb has a taller and wider

266 envelope than the right hind limb in this trial, but as vector and SPM analysis found no

267 significant differences between hindlimbs, this only illustrates between limb variability that may 268 occur.

269 The statistical relationships between traditional GRF variables and vector summary variables

270 (Table 5) indicate that VecMag was most strongly related $(\mathrm{R}>.9)$ with peak vertical forces

271 (forelimbs $\mathrm{p}<.001$, hindlimbs $\mathrm{p}<.001$ ). For the forelimbs, VecMag was also strongly $(\mathrm{R}>.7)$

272 related with vertical impulse $(\mathrm{p}<.001)$, peak braking force $(\mathrm{p}<.001)$, and braking impulse

$273(\mathrm{p}<.001)$. The strongest relationships for VecAng were with peak braking force $(\mathrm{R}>.6$; forelimbs

$274 \mathrm{p}=.004$, hindlimbs $\mathrm{p}<.001)$, peak propulsive force in the forelimbs $(\mathrm{R}>.6$; forelimbs $\mathrm{p}=.005)$, 
275 braking impulse $(\mathrm{R}>.6$; forelimbs $\mathrm{p}=.006$, hindlimbs $\mathrm{p}<.001)$ and propulsive impulse $(\mathrm{R}>.6$;

276 forelimbs $\mathrm{p}=.002$, hindlimbs $\mathrm{p}=.001)$.

\section{Discussion}

278 This study illustrates the use of a potentially visually appealing and intuitive technique that 1)

279 condenses the large amount of information and numerous variables generated by traditional GRF

280 analysis into a single diagram with two summary variables, VecMag and VecAng, and 2)

281 describes a method for analyzing multi-dimensional continuous data. Comparisons of between

282 limb function by superimposition of their vector diagrams may be easier to visualize than more

283 traditional GRF curves and differences between the diagrams can be tested statistically using

284 summary vector variables. In addition, a better understanding of functional adaptations

285 throughout the stance phase may be achieved by SPM of continuous data. Subtle asymmetries in

286 subjectively sound horses were detected using the vector analysis and SPM, but only significantly

287 for the individual horse using SPM. The hypothesis can therefore be accepted, but variability and

288 directional bias in a group will affect the threshold limits and therefore level of significance using

289 SPM. Summary vector variables strongly correlated with traditional variables, so this hypothesis

290 was accepted.

291 Visual evaluation of force vector diagrams has previously been described and applied in human

292 biomechanical analysis under the name Pedotti diagram, which refers to the researcher who

293 initially described the method (Pedotti, 1977; Kambhampati, 2007; Marasović, Cecić and Zanchi,

294 2009) or butterfly diagram, which refers to the fact that a walking person generates a vector

295 envelope that is shaped like a butterfly wing (Khondadadeh, Whittle and Bremble, 1986; Berki et

296 al., 2015). We have used the more generic term force vector diagram, which is applicable to all 
297 gaits and all species. The potential advantages of force vector analysis over traditional GRF

298 analysis are that the diagrams may be easier to read and interpret by clinicians and researchers

299 who do not have detailed knowledge of biomechanics. They may also have practical applications

300 in evaluating gait asymmetries, and for monitoring changes over time in response to training or

301 rehabilitation.

302 The force vectors originate at the centre of pressure (COP) beneath the hoof and a greater vector 303 density indicates slower progression of the COP under the hoof (Nauwelaerts, Hobbs and Back, 304 2017), whereas more widely separated vectors occur when the COP is moving more rapidly.

305 Since the end point of each force vector is determined by the magnitude and direction of the 306 applied force, the vector envelope has a typical and different shape for the forelimb and hind limb 307 in accordance with their different functional responsibilities. In trot the envelopes have the shape 308 of a vertically-oriented ellipse. The envelope is taller and more caudally oriented in the forelimbs 309 in accordance with the higher vertical and braking forces compared with the hind limbs which 310 have a shorter and more cranially oriented envelope due to the higher propulsive forces. In the

311 forelimbs but not the hind limbs, the height of the envelope is expected to increase with trotting 312 speed as a consequence of the increase in forelimb vertical force (Dutto et al., 2004). Therefore, it 313 is important to consider the effects of speed when comparing force vector diagrams and to 314 investigate to what extent steady state locomotion was performed over the analysed stride cycle.

315 Evaluating force vector analysis and SPM against traditional methods of analysis, data for the 316 left-right and high-low comparisons for the group provided an insight into similarities and 317 differences in findings that may be expected. Greater braking GRF and impulse and a more 318 caudally aligned VecAng in the left forelimb when comparing left to right is illustrated in $\mathrm{T}^{2}$ plots 319 coming closer to the significance threshold in SPM for the forelimb. In contrast, when comparing 
320 the higher GRF diagonal pair to the lower, only the vertical GRF, impulses and VecMag in the

321 forelimb were significant, which is indicative of the re-classification of the diagonal pairs. For

322 SPM of high-low, $\mathrm{T}^{2}$ plots were further from the significance threshold and only closer around

323 the time of peak GRF in the forelimbs. Two possible approaches could explain the differences in

324 significance between methods. Either traditional and vector analysis yielded false positives,

325 unlike SPM analysis which uses random field theory to tightly control alpha (Pataky et al., 2016).

326 Alternatively, functional asymmetry in braking GRFs between left and right forelimbs is evident

327 and may relate to sidedness, but this is masked when grouping the diagonals by vertical GRFs. In

328 humans, dominant limbs (dominant being the right limb if right handed) are able to make well

329 directed, smooth and energy efficient movements, whereas non-dominant limb movements tend

330 to be less efficient (Sainsburg, 2014). In horses, evidence of sidedness is emerging, but habitual

331 postural and locomotor preferences are commonly linked to dorsal hoof wall angle differences

332 (van Heel et al., 2006). Greater braking forces have been reported in hooves with a flatter dorsal

333 hoof wall angle, but usually in combination with an increase in peak vertical force (Wiggers et

334 al., 2015). As such, these results do not consistently suggest that the group had a flatter hoof

335 angle in the left forelimb, but this may not preclude evidence of functional sidedness. As

336 asymmetric bias is of interest in horses, particularly when considering sub-clinical conditions, the

337 methods of analysis used in future studies should be an important consideration until we have a

338 clearer understanding of common functional adaptations.

339 The values for VecMag in both forelimbs and hind limbs were predominantly correlated with

340 forelimb peak forces and impulses for the vertical and braking GRF components. The force plate

341 and the measured GRF variables have been described as the gold standard in lameness diagnosis

342 (Keegan et al., 2011), with peak vertical GRF having the highest sensitivity and specificity for

343 classifying horses as lame versus sound (Ishihara et al., 2005). These authors suggest that a 7\% 
344 decrease in peak vertical GRF is equivalent to an increase of $0.5 / 5.0$ in the subjectively-assessed

345 lameness grade as described by the American Association of Equine Practitioners (American

346 Association of Equine Practitioners, 2017). Since VecMag represents the magnitude of limb

347 loading over the entire stance phase, it is anticipated that between-limb differences in VecMag

348 combined with the vector diagrams could be valuable for detecting and interpreting functional

349 asymmetry. Keegan (2007) highlighted the fact that some lameness conditions, notably mild

350 superficial digital flexor tendinopathy and navicular disease, are associated with a change in

351 shape of the vertical GRF curve rather than simply a reduction in peak vertical GRF in the lame

352 limb (Williams et al.,1999). In these cases, the shape change involved a decrease in vertical GRF

353 in the early (superficial digital flexor tendinopathy) or later (navicular disease) part of stance,

354 with the timing being related to the function of the affected structures. Changes of this nature

355 should be visible on vector diagrams and detectable using SPM, and may be interpreted in light

356 of knowledge about which structures are active at different times during the stance phase. Thus,

357 the shape of the vector diagram and the timing of asymmetries detected by SPM might contain

358 potentially useful information to aid in localizing some physiological adaptations that have

359 functional consequences.

360 The SPM method was initially used for analysis of brain images (Penny et al., 2007). However,

361 the ability to detect changes in time-series data lends itself to the analysis of biomechanical data,

362 as functional adaptations may not be fully captured when the analysis is confined to discrete

363 variables representing single events (Pataky, Robinson and Vanrenterghem, 2013). SPM analysis

364 might prove to be useful for detecting asymmetries in the individual horse due to sidedness. This

365 was illustrated in horse 10 which was assessed clinically as being sound. Even though peak

366 vertical force differed significantly between the forelimbs (due to a directional bias), the

367 magnitude of the difference $(2.7 \%)$ was less than the threshold value used to detect subclinical 
368 lameness on the treadmill (Weishaupt et al., 2006). Therefore, it is not surprising that the horse

369 was subjectively assessed as sound. In this horse SPM revealed three periods of asymmetry in the

370 forelimbs. If these periods of asymmetry can be related to specific events in the stride cycle, then

371 it may facilitate interpretation of their functional significance. When biomechanical data are

372 averaged over a group of horses, much of the individual variability tends to be lost. In order to

373 further the understanding of locomotor asymmetries, for example sidedness due to cerebral

374 laterality, it might prove useful to evaluate horses on an individual basis and to explore

375 asymmetry throughout the stride rather than at discrete time points. The results present a

376 preliminary indication that SPM may prove useful for this purpose.

377 In horse 10 SPM identified three time periods when the forces differed significantly between left 378 and right forelimbs coinciding with secondary impact (Gustas, Johnston and Drevemo, 2006), 379 peak vertical force (Hobbs and Clayton, 2013), and heel lift (Merkens and Schamhardt, 1994). 380 Therefore, it seems plausible that there are functional inter-limb differences at these times. In 381 general the results of traditional force plate analysis, force vector analysis and SPM analysis are 382 in agreement. For example, the mid-stance difference between left and right forelimbs identified 383 by SPM is consistent with the difference in forelimb peak vertical force identified by traditional 384 statistical analysis and with the difference in VecMag identified by the force vector diagrams and 385 analysis (Figure 6).

386 In the forelimb and hind limb, VecAng is highly correlated with the peak longitudinal forces and 387 longitudinal impulses indicating that it represents the longitudinal GRF effects. High variability 388 in longitudinal GRFs has previously been reported in non-lame horses and horses with low grade $389(1 / 5)$ lameness, which led to the conclusion that longitudinal GRFs were not useful for 390 quantifying lameness grade (Ishihara et al., 2005). The between- and within-horse variability 391 reported in that study concur with our findings and may reflect the need for the horse to adjust its 
392 balance from stride to stride (Clayton and Hobbs, 2017). The between-limb differences are

393 particularly striking when the vector diagrams for left and right limbs are overlaid to show the

394 relative lengths and angles of the vectors (Figure 6).

395 At steady-state gait one might expect the summed vertical impulses for the diagonal pairs to be 396 equal and the longitudinal impulses summed over both diagonal pairs to be zero (Hobbs and 397 Clayton, 2013; Lee, Bertram and Todhunter, 1999). The functional role of the forelimbs is to 398 provide a mechanism to alter the centre of mass (COM) trajectory from forwards and downwards 399 at diagonal contact to forwards and upwards at diagonal lift off (Bertram and Gutmann, 2008). In 400 horses, the large forelimb vertical impulses elevate the COM (Weishaupt et al., 2009; Clayton, 401 Schamhardt and Hobbs, 2017; Clayton and Hobbs, 2017) and increase nose-up pitching moments 402 (Hobbs, Bertram and Clayton, 2016). Asymmetries between left and right limbs and diagonals 403 may or may not be repeated consistently from step to step, as they reflect the need for subtle 404 adjustments of balance within a single stride (Hobbs, Bertram and Clayton, 2016). This is 405 particularly evident in the hindlimbs, as no significant differences were found in the group 406 analyses. Therefore, asymmetries in force vector diagrams that are present inconsistently should 407 be considered with caution with respect to lameness.

408 Limitations exist in using force vector analysis and SPM over more traditional methods. Force 409 vector analysis, in particular VecMag is sensitive to the method used to define the stance phase, 410 as the vector is divided by the number of samples (see Supplementary Information). It is

411 therefore important to report the threshold used to define the stance phase and it would be 412 preferable to adopt a standard threshold in the future. For SPM, due to the tight control of alpha, 413 reaching significance may not be as important as understanding the clinical implications of 
414 functional adaptations seen throughout the entire stance phase. This should be taken into

415 consideration when using SPM to study asymmetry within groups of horses.

\section{Conclusion}

418 This study illustrates the application of force vector analysis as a visual tool that can be used to

419 evaluate and compare GRFs between limbs and horses. The present study is a 2D analysis in the

420 sagittal plane but can be applied to other 2D planes and extended to 3D data. Two summary

421 vector variables that represent the overall effect of the applied force during the entire stance

422 phase are presented; VecMag correlates with the vertical force and impulse and VecAng

423 correlates with the longitudinal force and impulse. Vector diagrams are used to display and

424 compare sagittal plane GRFs throughout stance. Statistical analysis of the force vectors using

425 Statistical Parametric Mapping shows promise as a tool to detect subtle inter-limb asymmetries at

426 defined time periods that correspond with specific kinematic events.

\section{References}

428 American Association of Equine Practitioners. 2017. Lameness exams: evaluating the lame horse.

429 https://aaep.org/horsehealth/lameness-exams-evaluating-lame-horse

430 Back W, MacAllister CG, Heel MCV van, Pollmeier M, Hanson PD. 2007. Vertical frontlimb

431 ground reaction forces of sound and lame warmbloods differ from those in Quarter Horses.

432 Journal of Equine Veterinary Science 27, 123-129. 
433 Berki V, Boswell MA, Ciltea D, Guseila LM, Goss L, Barnes S, McMillan GR, Davis BL. 2015.

434 Expanded butterfly plots: A new method to analyze simultaneous pressure and shear on the 435 plantar skin surface during gait. Journal of Biomechanics 48, 2214-2216.

436 Bertram JEA, Lee DV, Case HN and Todhunter RJ. 2000. Comparison of the trotting gaits of 437 Labrador Retrievers and Greyhounds. American Journal of Veterinary Research 61:7:832-838.

438 Bertram JEA, Gutmann A. 2009. Motions of the running horse and cheetah revisited:

439 fundamental mechanics of the transverse and rotary gallop, Journal of the Royal Society 440 Interface 6, 549-59.

441 Bidwell LA, Brown KE, Cordier A, Mullineaux DR, Clayton HM. 2004. Mepivacaine local 442 anesthetic duration in equine palmar digital nerve blocks. Equine Veterinary Journal 36, 723-726. 443 Clayton HM, Schamhardt HC, Hobbs SJ. 2017. Ground reaction forces of elite dressage horses in 444 collected trot and passage. The Veterinary Journal 221, 30-33. doi.org/10.1016/j.tvj1.2017.01.016

445 Clayton HM, Hobbs SJ. 2017. An exploration of strategies used by dressage horses to control 446 moments around the centre of mass when performing passage. PeerJ 5:e3866; DOI $447 \quad 10.7717 /$ peerj. 3866

448 Dow SM, Leendertz JA, Silver IA, Goodship AE. 1991. Identification of subclinical tendon 449 injury from ground reaction force analysis. Equine Veterinary Journal 23(4), 266-272.

450 Dutto DJ, Hoyt DF, Cogger EA, Wickler SJ. 2004. Ground reaction forces in horses trotting up an 451 incline and on the level over a range of speeds. Journal of Experimental Biology 207, 3507-3514. 
452 Gustås P, Johnston C, Drevemo S. 2006. Ground reaction force and hoof deceleration patterns on

453 two different surfaces at the trot. Equine and Comparative Exercise Physiology 3, 209-216.

454 https://doi.org/10.1017/S147806150667607X

455 Hobbs SJ, Clayton HM. 2013. Sagittal plane ground reaction forces, centre of pressure and centre 456 of mass in trotting horses. The Veterinary Journal 198, e14-e19.

457 Hobbs SJ, Bertram J, Clayton HM. 2016. The influence of diagonal dissociation and speed on 458 locomotor parameters in trotting horses. PeerJ 4:e2190 https://doi.org/10.7717/peerj.2190.

459 Ishihara A, Bertone AL, Rajala-Schultz PJ. 2005 Association between subjective lameness grade 460 and kinetic gait parameters in horses with experimentally induced forelimb lameness. American 461 Journal of Veterinary Research 66, 1805-1815.

462 Kambhampati SBS. 2007. Constructing a Pedotti diagram using Excel charts. Journal of 463 Biomechanics 40, 16:3748-3750.

464 Keegan KG. 2007. Evidence-based lameness detection and quantification. Veterinary Clinics of 465 North America: Equine Practice 23, 403-423.

466 Keegan KG, Kramer J, Yonezawa Y, Maki H, Pai PF, Dent EV, Kellerman TE, Wilson DA, Reed 467 SK. 2011. Assessment of repeatability of a wireless, inertial sensor-based lameness evaluation 468 system for horses. American Journal of Veterinary Research 72, 1156-1163. 
469 Khondadadeh S, Whittle MW, Bremble GR. 1986. Height of centre of body mass during 470 osteoarthritic gait. Clinical Biomechanics 1, 77-80.

471 Khumsap S, Clayton HM, Lanovaz JL. 2001. Effect of walking velocity ground reaction force 472 variables in the hind limb of clinically normal horses. American Journal of Veterinary Research $473 \quad 62,901-906$.

474 Khumsap S, Lanovaz JL, Rosenstein DL, Byron C, Clayton HM. 2003. Effect of unilateral 475 synovitis of distal intertarsal and tarsometatarsal joints on sagittal plane kinematics and kinetics 476 of trotting horses. American Journal of Veterinary Research 64, 1491-1495.

477 Lee DV, Bertram JEA, Todhunter RJ. 1999. Acceleration and balance in trotting dogs. Journal of 478 Experimental Biology 202, 3565-3573.

479 Marasović T, Cecić M, Zanchi V. 2009. Analysis and interpretation of ground reaction forces in 480 normal gait. WSEAS Transactions on Systems 8, 1105-1114.

481 McLaughlin RM, Gaughan EM, Roush K, Skaggs C. 1996. Effects of subject velocity on ground 482 reaction force measurements and stance times in clinically normal horses at the walk and trot. 483 American Journal of Veterinary Research 57, 7-11.

484 Merkens HW, Schamhardt HC. 1988. Evaluation of equine locomotion during different degrees 485 of experimentally induced lameness 1: Lameness model and quantification of ground reaction 486 force patterns of the limbs. Equine Veterinary Journal 20, (Supplement 6), 99-106. 
487 Merkens HW, Schamhardt HC. 1994. Relationships between ground reaction force patterns and 488 kinematics in the walking and trotting horse. Equine Veterinary Journal 26, (Supplement 17), 6748970.

490 Merkens HW, Schamhardt HC, Hartman W, Kersjes AW. 1986. Ground reaction force patterns of 491 Dutch Warmblood horses at normal walk. Equine Veterinary Journal 18, 207-214.

492 Merkens HW, Schamhardt HC, Hartman W, Kersjes AW. 1988. The use of Horse(INDEX), a 493 method of analysing the ground reaction force patterns of lame and normal gaited horses at the 494 walk. Equine Veterinary Journal 20, 29-36.

495 Merkens HW, Schamhardt HC, Osch GJVM, Bogert AJ. 1993a Ground reaction force patterns of 496 Dutch Warmblood horses at normal trot. Equine Veterinary Journal 25, 134-137.

497 Merkens HW, Schamhardt HC, Osch GJVM van, Hartman W. 1993b. Ground reaction force 498 patterns of Dutch Warmbloods at canter. American Journal of Veterinary Research 54, 670-674.

499 Nauwelaerts S, Hobbs SJ, Back W. 2017. A horse's locomotor signature: COP path determined by 500 the individual limb. PLoS ONE 12 (2): e0167477. doi:10.1371/journal.pone.0167477

501 Pataky TC. 2012. One-dimensional statistical parametric mapping in Python. Computer Methods 502 in Biomechanics and Biomedical Engineering 15, 295-301, DOI:10.1080/10255842.2010.527837 
503 Pataky TC, Robinson MA, Vanrenterghem J. 2013. Vector field statistical analysis of kinematic 504 and force trajectories. Journal of Biomechanics 46, 2394-2401.

505 doi:10.1016/j.jbiomech.2013.07.031

506 Pataky TC, Vanrenterghem J, Robinson MA. 2016. The probability of false positives in zero507 dimensional analyses of one-dimensional kinematic, force and EMG trajectories. Journal of 508 Biomechanics 49, (9), 1468-1476. doi:10.1016/j.jbiomech.2016.03.032

509 Pearce GP, May-Davis S, Greaves D. 2005. Femoral asymmetry in the Thoroughbred racehorse. 510 Veterinary Journal 83, (6), 367-370.

511 Pedotti A. 1977. Simple equipment used in clinical practice for evaluation of locomotion. IEEE 512 Transactions on Biomedical Engineering 24, 456-461.

513 Penny W, Friston K, Ashburner J, Kiebel S, Nichols T. 2007. IN: Statistical parametric mapping: 514 the analysis of functional brain images. DOI:10.1016/B978-0-12-372560-8.X5000-1

515 Riemersma DJ, van den Bogert AJ, Jansen MO, Schamhardt HC. 1996. Influence of shoeing on 516 ground reaction forces and tendon strain in the forelimbs of ponies. Equine Veterinary Journal 517 28, 126-132. DOI: 10.1111/j.2042-3306.1996.tb01604.x

518 Sainsburg RL. 2014. Convergent models of handedness and brain lateralization. Frontiers in 519 Psychology 5, 1092, 1-14. DOI: 10.3389/fpsyg.2014.01092 
520 Starke SD, Raistrick KJ, May SA, Pfau T. 2013. The effect of trotting speed on the evaluation of

521 subtle lameness in horses. Veterinary Journal 197, 245-252.

522 Stubbs NC, Riggs CM, Hodges PW, Jeffcott LB, Hodgson DR, Clayton HM, McGowan CM.

523 2010. Osseous spinal pathology and epaxial muscle ultrasonography in Thoroughbred racehorses.

524 Equine Veterinary Journal 42, (s38), 654-661.

525 van Heel MC V, Kroekenstoel AM, Van Dierendonck MC, van Weeren PR, Back W. 2006.

526 Uneven feet in a foal may develop as a consequence of lateral grazing behaviour induced by

527 conformational traits. Equine Veterinary Journal 38, 646-651.

528 Weishaupt MA, Wiestner T, Hogg HP, Jordan P, Auer JA. 2004a. Vertical ground reaction force-

529 time histories of sound Warmblood horses trotting on a treadmill. The Veterinary Journal 168, $530 \quad 304-311$.

531 Weishaupt MA, Wiestner T, Hogg HP, Jordan P, Auer JA. 2004b. Compensatory load

532 redistribution of horses with induced weightbearing hind limb lameness trotting on a treadmill.

533 Equine Veterinary Journal 36, 727-733.

534 Weishaupt MA Wiestner T, Hogg HP, Jordan P, Auer JA. 2006. Compensatory load redistribution 535 of horses with induced weight-bearing forelimb lameness trotting on a treadmill. The Veterinary 536 Journal 171, 135-146.

537 Weishaupt M. 2008. Adaptation strategies of horses with lameness. Veterinary Clinics of North 538 America: Equine Practice 24, 79-100. 
539 Weishaupt MA, Byström K, Von Peinen T, Weistner H, Meyer H, Waldern N, Johnston C, van

540 Weeren R, Roepstorff L. 2009. Kinetics and kinematics of the passage. Equine Veterinary

541 Journal 41, 263-267.

542 Wiggers N, Nauwelaerts S, Hobbs SJ, Bool S, Wolschrijn CF, Back W. 2015. Functional

543 locomotor consequences of uneven forefeet for trot symmetry in individual riding horses. PLOS

544 ONE 10(2): e0114836. https://doi.org/10.1371/journal.pone.0114836

545 Williams GE, Silverman BW, Wilson AM, Goodship AE. 1999. Pathology-specific changes in

546 equine ground reaction force data demonstrated by principal component analysis. American

547 Journal of Veterinary Research 60, 549-555.

\section{$548 \quad$ Figure Legends}

549 Figure 1: Force vector diagram for a forelimb of a horse trotting overground. Sagittal plane force 550 vectors (dark red lines) are constructed at intervals of $0.0083 \mathrm{~s}$. Each vector originates at its 551 centre of pressure, which is identified relative to the hoof location on the force plate. The length 552 is proportional in magnitude to that of the force and it is oriented in the direction of the force. The 553 vector envelope joins the peripheral tips of the force vectors. The black vertical line is drawn 554 through the dorsopalmar midpoint of the hoof. The summary vector is shown as a heavy red line 555 originating at the midpoint of the hoof; its length represents the mean magnitude (VecMag) and 556 its angle to the vertical represents the mean angle (VecAng) of all vectors throughout the stance 557 phase. 
558 Figure 2: Stick figures, time-normalized vertical and longitudinal ground reaction forces and

559 vector diagrams for the two diagonals of one consecutive stride from one horse trotting

560 overground. A) Sequential stick figures of the horse at 10\% intervals of the stride. B) Vertical

561 ground reaction forces $(\mathrm{N} / \mathrm{kg})$ for the fore and hind limbs of each diagonal pair. C) Longitudinal

562 ground reaction forces $(\mathrm{N} / \mathrm{kg})$ for the fore and hind limbs of each diagonal pair. D) Vector

563 diagrams constructed from the force data in B and C showing summary vectors for each limb

564 (summary vectors shown in black). Blue: left forelimb; red: right forelimb; orange: right hind

565 limb; green: left hind limb.RH: right hind; LF: left fore; LH: left hind; RF: right fore; LFRH: left

566 fore and right hind diagonal; RFLH: right fore and left hind diagonal.

567 Figure 3: Results of statistical parametric mapping of ground reaction forces at trot overground

568 for a group of 10 horses (mean of 3 stance phases per horse, per limb). A) The Hotelling's $T^{2}$ test

569 results (vertical and longitudinal ground reaction forces combined), the $T^{2}$ statistic (black line)

570 did not exceed the critical threshold (red dashed line) therefore there were no statistical

571 differences. B) mean (solid line) and standard deviation (shaded area) vertical and C) mean (solid

572 line) and standard deviation (shaded area) longitudinal ground reaction forces for the group

573 (N/kg). Blue: left forelimb; red: right forelimb; orange: right hind limb; green: left hind limb.

574 Figure 4: Results of statistical parametric mapping of ground reaction forces of trot overground

575 for a group of 10 horses when categorized by higher and lower forelimb peak vertical GRF (mean

576 of 3 stance phases per horse, per limb). A) The Hotelling's $T^{2}$ test SPM results (vertical and

577 longitudinal ground reaction forces combined), the $T^{2}$ statistic did not exceed the critical threshold

578 (red dashed line) therefore there were no statistical differences. B) mean (solid line) and standard

579 deviation (shaded area) vertical and C) mean (solid line) and standard deviation (shaded area)

580 longitudinal ground reaction forces for the group (N/kg). Red: forelimb with higher peak vertical 
581 GRF; Blue: forelimb with lower peak vertical GRF; orange: diagonal hind limb of the forelimb 582 with higher peak vertical GRF; green: diagonal hind limb of the forelimb with lower peak vertical 583 GRF.

584 Figure 5: Results of statistical parametric mapping of ground reaction forces of trot overground 585 for one horse (8 stance phases per limb). A) The Hotelling's $T^{2}$ test SPM results (vertical and 586 longitudinal ground reaction forces combined), the $T^{2}$ statistic crossed the critical threshold in 587 three regions indicating that there was a significant differences in the forelimbs, B) mean (solid 588 line) and standard deviation (shaded area) vertical ground reaction forces $(\mathrm{N} / \mathrm{kg}), \mathrm{C})$ post-hoc 589 paired-samples $\operatorname{SPM}(\mathrm{t})$ results for the vertical force component, D) mean (solid line) and standard 590 deviation (shaded area) longitudinal ground reaction forces $(\mathrm{N} / \mathrm{kg})$, and $\mathrm{E})$ post-hoc paired591 samples $\operatorname{SPM}(\mathrm{t})$ results for the longitudinal force component for horse 10 Blue: left forelimb; red: 592 right forelimb; orange: right hind limb; green: left hind limb.

593 Figure 6: Force vector diagrams overlaid for contralateral limbs of horse 10 trotting overground.

594 RH: right hind; LF: left fore; LH: left hind; RF: right fore. 


\section{Table $\mathbf{1}$ (on next page)}

Classification of the group of horses.

Directional asymmetry information from peak forelimb GRF $(\mathrm{N} / \mathrm{kg})$ measured for each stance phase for the 10 horses in the group. 


\begin{tabular}{|l|l|l|l|l|}
\hline $\begin{array}{l}\text { Higher Peak } \\
\text { Forelimb GRF }\end{array}$ & \# horses & $\begin{array}{l}\text { \# horses with } \\
\text { all 3 trials }>\end{array}$ & $\begin{array}{l}\text { \# horses with }>4 \% \\
\text { difference in peak GRF }\end{array}$ & $\begin{array}{l}\text { Range of mean difference in } \\
\text { peak forelimb GRF (\%) }\end{array}$ \\
\hline Left & 6 & 4 & 2 & $<0.01$ to 5.9 \\
\hline Right & 4 & 3 & 1 & 0.8 to 3.4 \\
\hline
\end{tabular}




\section{Table 2 (on next page)}

Typical force and vector summary variables for the group comparing left diagonal to right diagonal.

Mean, standard deviation (s.d.) and coefficient of variation (COV) ([range] for VecAng) of typical force variables and vector summary variables for left and right fore and hind limbs for the group of 10 horses trotting in hand, overground. Significant differences between left and right limbs are shaded. Simple bootstrapping was applied to variables denoted with an asterisk*. 


\begin{tabular}{|c|c|c|c|c|c|c|}
\hline Variable & Limb & $\mathrm{L} / \mathrm{R}$ & Mean (s.d.) & $\begin{array}{c}\mathrm{COV}(\%) \\
\text { [Range] }\end{array}$ & $\begin{array}{c}\mathrm{P} \\
\text { value }\end{array}$ & Bootstrap \\
\hline \multirow{4}{*}{$\begin{array}{l}\text { Peak Vertical GRF } \\
(\mathrm{N} / \mathrm{kg})\end{array}$} & \multirow[t]{2}{*}{ Fore } & $\mathrm{L}$ & $10.9(0.73)$ & 6.7 & \multirow[t]{2}{*}{.527} & \\
\hline & & $\mathrm{R}$ & $10.8(0.59)$ & 5.5 & & \\
\hline & \multirow[t]{2}{*}{ Hind } & $\mathrm{L}$ & $8.6(0.49)$ & 5.7 & \multirow[t]{2}{*}{.476} & \\
\hline & & $\mathrm{R}$ & $8.7(0.74)$ & 8.5 & & \\
\hline \multirow{4}{*}{$\begin{array}{l}\text { Peak Braking GRF } \\
(\mathrm{N} / \mathrm{kg})\end{array}$} & \multirow[t]{2}{*}{ Fore } & $\mathrm{L}$ & $-1.17(0.19)$ & 16.2 & \multirow[t]{2}{*}{.044} & \\
\hline & & $\mathrm{R}$ & $-1.07(0.13)$ & 12.4 & & \\
\hline & \multirow[t]{2}{*}{ Hind } & $\mathrm{L}$ & $-0.70(0.18)$ & 25.9 & \multirow[t]{2}{*}{.251} & \\
\hline & & $\mathrm{R}$ & $-0.65(0.07)$ & 11.0 & & \\
\hline \multirow{4}{*}{$\begin{array}{l}\text { Peak Propulsive GRF } \\
(\mathrm{N} / \mathrm{kg})\end{array}$} & \multirow[t]{2}{*}{ Fore } & $\mathrm{L}$ & $0.87(0.14)$ & 15.6 & \multirow[t]{2}{*}{.083} & \\
\hline & & $\mathrm{R}$ & $0.92(0.12)$ & 12.9 & & \\
\hline & \multirow[t]{2}{*}{ Hind } & $\mathrm{L}$ & $1.02(0.10)$ & 9.8 & \multirow[t]{2}{*}{.524} & $*$ \\
\hline & & $\mathrm{R}$ & $1.08(0.10)$ & 8.8 & & \\
\hline \multirow{4}{*}{$\begin{array}{l}\text { Vertical Impulse } \\
(\mathrm{Ns} / \mathrm{kg})\end{array}$} & \multirow[t]{2}{*}{ Fore } & $\mathrm{L}$ & $1.98(0.17)$ & 8.6 & \multirow[t]{2}{*}{.216} & \\
\hline & & $\mathrm{R}$ & $1.95(0.19)$ & 9.5 & & \\
\hline & \multirow[t]{2}{*}{ Hind } & $\mathrm{L}$ & $1.41(0.12)$ & 8.7 & \multirow[t]{2}{*}{.348} & \\
\hline & & $\mathrm{R}$ & $1.43(0.15)$ & 10.1 & & $*$ \\
\hline \multirow{4}{*}{$\begin{array}{l}\text { Braking Impulse } \\
(\mathrm{Ns} / \mathrm{kg})\end{array}$} & \multirow[t]{2}{*}{ Fore } & $\mathrm{L}$ & $-0.12(0.02)$ & 12.6 & \multirow[t]{2}{*}{.020} & \\
\hline & & $\mathrm{R}$ & $-0.11(0.01)$ & 11.5 & & \\
\hline & \multirow[t]{2}{*}{ Hind } & $\mathrm{L}$ & $-0.06(0.02)$ & 33.3 & \multirow[t]{2}{*}{.131} & \\
\hline & & $\mathrm{R}$ & $-0.05(0.01)$ & 14.8 & & \\
\hline \multirow{3}{*}{$\begin{array}{l}\text { Propulsive Impulse } \\
\text { (Ns/kg) }\end{array}$} & \multirow[t]{2}{*}{ Fore } & $\mathrm{L}$ & $0.07(0.01)$ & 19.5 & \multirow[t]{2}{*}{.062} & $*$ \\
\hline & & $\mathrm{R}$ & $0.08(0.01)$ & 16.5 & & \\
\hline & Hind & $\mathrm{L}$ & $0.08(0.01)$ & 14.0 & .072 & \\
\hline
\end{tabular}


Manuscript to be reviewed

\begin{tabular}{|c|c|c|c|c|c|c|}
\hline & & $\mathrm{R}$ & $0.09(0.01)$ & 15.6 & & \\
\hline \multirow{4}{*}{$\begin{array}{l}\text { Time to Peak Vertical } \\
\text { GRF (\% stance) }\end{array}$} & \multirow[t]{2}{*}{ Fore } & $\mathrm{L}$ & $45.1(1.8)$ & 3.9 & \multirow[t]{2}{*}{.265} & \\
\hline & & $\mathrm{R}$ & $45.6(2.3)$ & 5.0 & & \\
\hline & \multirow[t]{2}{*}{ Hind } & $\mathrm{L}$ & $44.3(2.3)$ & 5.1 & \multirow[t]{2}{*}{.554} & $*$ \\
\hline & & $\mathrm{R}$ & $44.7(1.1)$ & 2.4 & & \\
\hline \multirow{4}{*}{$\begin{array}{l}\text { Time to Peak Braking } \\
\text { Force ( } \% \text { stance })\end{array}$} & \multirow[t]{2}{*}{ Fore } & $\mathrm{L}$ & $28.8(3.2)$ & 11.2 & \multirow[t]{2}{*}{.424} & \\
\hline & & $\mathrm{R}$ & $29.4(4.5)$ & 15.4 & & \\
\hline & \multirow[t]{2}{*}{ Hind } & $\mathrm{L}$ & $21.3(1.5)$ & 6.8 & \multirow[t]{2}{*}{.113} & \\
\hline & & $\mathrm{R}$ & $20.1(1.8)$ & 8.9 & & \\
\hline \multirow{4}{*}{$\begin{array}{l}\text { Time to Peak } \\
\text { Propulsive Force ( } \% \\
\text { stance) }\end{array}$} & \multirow[t]{2}{*}{ Fore } & $\mathrm{L}$ & $73.7(1.9)$ & 3.5 & \multirow[t]{2}{*}{.401} & \\
\hline & & $\mathrm{R}$ & $73.2(3.1)$ & 4.6 & & \\
\hline & \multirow[t]{2}{*}{ Hind } & $\mathrm{L}$ & $63.4(3.1)$ & 6.0 & \multirow[t]{2}{*}{.263} & $*$ \\
\hline & & $\mathrm{R}$ & $62.6(1.9)$ & 3.7 & & \\
\hline \multirow{4}{*}{$\begin{array}{l}\text { Vector Magnitude } \\
(\mathrm{N} / \mathrm{kg})\end{array}$} & \multirow[t]{2}{*}{ Fore } & $\mathrm{L}$ & $6.47(0.50)$ & 7.8 & \multirow[t]{2}{*}{.345} & \\
\hline & & $\mathrm{R}$ & $6.40(0.42)$ & 6.6 & & \\
\hline & \multirow[t]{2}{*}{ Hind } & $\mathrm{L}$ & $4.99(0.30)$ & 6.1 & \multirow[t]{2}{*}{.123} & \\
\hline & & $\mathrm{R}$ & $5.09(0.37)$ & 7.4 & & \\
\hline \multirow[t]{4}{*}{ Vector Angle (degrees) } & \multirow[t]{2}{*}{ Fore } & $\mathrm{L}$ & $-1.56(0.50)$ & {$[-0.82,-2.36]$} & \multirow[t]{2}{*}{.022} & \\
\hline & & $\mathrm{R}$ & $-1.09(0.44)$ & {$[-0.13,-1.63]$} & & \\
\hline & \multirow[t]{2}{*}{ Hind } & $\mathrm{L}$ & $1.08(1.04)$ & {$[2.39,-0.77]$} & \multirow[t]{2}{*}{.103} & $*$ \\
\hline & & $\mathrm{R}$ & $1.61(0.46)$ & {$[2.02,0.80]$} & & \\
\hline
\end{tabular}




\section{Table 3 (on next page)}

Typical force and vector summary variables for the group comparing high GRF diagonal to low GRF diagonal.

Mean, standard deviation (s.d.) and coefficient of variation (COV) ([range] for VecAng) of typical force variables and vector summary variables for high peak forelimb force diagonal and low peak forelimb force diagonal for the group of 10 horses trotting in hand, overground. Significant differences between left and right limbs are shaded. Simple bootstrapping was applied to variables denoted with an asterisk*. 


\begin{tabular}{|c|c|c|c|c|c|c|}
\hline Variable & Limb & $\mathrm{H} / \mathrm{L}$ & Mean (s.d.) & $\begin{array}{l}\mathrm{COV}(\%) \\
\text { [Range] }\end{array}$ & $\begin{array}{c}\mathrm{P} \\
\text { value }\end{array}$ & Bootstrap \\
\hline \multirow{4}{*}{$\begin{array}{l}\text { Peak Vertical GRF } \\
(\mathrm{N} / \mathrm{kg})\end{array}$} & \multirow[t]{2}{*}{ Fore } & $\mathrm{H}$ & $11.0(0.67)$ & 6.1 & \multirow[t]{2}{*}{.003} & \\
\hline & & $\mathrm{L}$ & $10.8(0.63)$ & 5.9 & & \\
\hline & \multirow[t]{2}{*}{ Hind } & $\mathrm{H}$ & $8.6(0.65)$ & 7.6 & \multirow[t]{2}{*}{.240} & \\
\hline & & $\mathrm{L}$ & $8.7(0.59)$ & 6.8 & & \\
\hline \multirow{4}{*}{$\begin{array}{l}\text { Peak Braking GRF } \\
(\mathrm{N} / \mathrm{kg})\end{array}$} & \multirow[t]{2}{*}{ Fore } & $\mathrm{H}$ & $-1.16(0.19)$ & 16.5 & \multirow[t]{2}{*}{.061} & \\
\hline & & $\mathrm{L}$ & $-1.08(0.13)$ & 12.0 & & \\
\hline & \multirow[t]{2}{*}{ Hind } & $\mathrm{H}$ & $-0.66(0.09)$ & 13.6 & \multirow[t]{2}{*}{.657} & \\
\hline & & $\mathrm{L}$ & $-0.68(0.17)$ & 25.7 & & $*$ \\
\hline \multirow{4}{*}{$\begin{array}{l}\text { Peak Propulsive GRF } \\
(\mathrm{N} / \mathrm{kg})\end{array}$} & \multirow[t]{2}{*}{ Fore } & $\mathrm{H}$ & $0.89(0.13)$ & 14.4 & \multirow[t]{2}{*}{.772} & \\
\hline & & $\mathrm{L}$ & $0.90(0.13)$ & 14.6 & & \\
\hline & \multirow[t]{2}{*}{ Hind } & $\mathrm{H}$ & $1.03(0.09)$ & 8.9 & \multirow[t]{2}{*}{.293} & \\
\hline & & $\mathrm{L}$ & $1.07(0.11)$ & 10.1 & & \\
\hline \multirow{4}{*}{$\begin{array}{l}\text { Vertical Impulse } \\
(\mathrm{Ns} / \mathrm{kg})\end{array}$} & \multirow[t]{2}{*}{ Fore } & $\mathrm{H}$ & $1.99(0.18)$ & 9.1 & \multirow[t]{2}{*}{.005} & \\
\hline & & $\mathrm{L}$ & $1.93(0.17)$ & 8.8 & & \\
\hline & \multirow[t]{2}{*}{ Hind } & $\mathrm{H}$ & $1.42(0.14)$ & 9.8 & \multirow[t]{2}{*}{.615} & \\
\hline & & $\mathrm{L}$ & $1.43(0.13)$ & 9.0 & & \\
\hline \multirow{4}{*}{$\begin{array}{l}\text { Braking Impulse } \\
(\mathrm{Ns} / \mathrm{kg})\end{array}$} & \multirow[t]{2}{*}{ Fore } & $\mathrm{H}$ & $-0.12(0.02)$ & 15.2 & \multirow[t]{2}{*}{.074} & \\
\hline & & $\mathrm{L}$ & $-0.11(0.01)$ & 8.3 & & \\
\hline & \multirow[t]{2}{*}{ Hind } & $\mathrm{H}$ & $-0.05(0.01)$ & 19.8 & \multirow[t]{2}{*}{.789} & \\
\hline & & $\mathrm{L}$ & $-0.05(0.02)$ & 34.2 & & \\
\hline \multirow{4}{*}{$\begin{array}{l}\text { Propulsive Impulse } \\
\text { (Ns/kg) }\end{array}$} & \multirow[t]{2}{*}{ Fore } & $\mathrm{H}$ & $0.07(0.01)$ & 18.7 & \multirow[t]{2}{*}{.662} & \\
\hline & & $\mathrm{L}$ & $0.08(0.01)$ & 18.1 & & \\
\hline & \multirow[t]{2}{*}{ Hind } & $\mathrm{H}$ & $0.09(0.01)$ & 13.6 & \multirow[t]{2}{*}{.494} & \\
\hline & & $\mathrm{L}$ & $0.09(0.02)$ & 17.1 & & \\
\hline
\end{tabular}


Manuscript to be reviewed

\begin{tabular}{|c|c|c|c|c|c|c|}
\hline \multirow{4}{*}{$\begin{array}{l}\text { Time to Peak Vertical } \\
\text { GRF (\% stance) }\end{array}$} & \multirow[t]{2}{*}{ Fore } & $\mathrm{H}$ & $45.3(1.87)$ & 4.1 & \multirow[t]{2}{*}{.765} & \\
\hline & & $\mathrm{L}$ & $45.4(2.20)$ & 4.9 & & \\
\hline & \multirow[t]{2}{*}{ Hind } & $\mathrm{H}$ & $44.5(2.29)$ & 5.1 & \multirow[t]{2}{*}{.926} & $*$ \\
\hline & & $\mathrm{L}$ & $44.5(1.07)$ & 2.4 & & * \\
\hline \multirow{4}{*}{$\begin{array}{l}\text { Time to Peak Braking } \\
\text { Force (\% stance) }\end{array}$} & \multirow[t]{2}{*}{ Fore } & $\mathrm{H}$ & $28.8(3.70)$ & 12.8 & \multirow[t]{2}{*}{.514} & \\
\hline & & $\mathrm{L}$ & $29.3(4.17)$ & 14.2 & & \\
\hline & \multirow[t]{2}{*}{ Hind } & $\mathrm{H}$ & $20.4(2.20)$ & 10.8 & \multirow[t]{2}{*}{.408} & \\
\hline & & $\mathrm{L}$ & $21.0(1.02)$ & 4.8 & & \\
\hline \multirow{4}{*}{$\begin{array}{l}\text { Time to Peak } \\
\text { Propulsive Force ( } \% \\
\text { stance) }\end{array}$} & \multirow[t]{2}{*}{ Fore } & $\mathrm{H}$ & $73.7(2.31)$ & 3.1 & \multirow[t]{2}{*}{.238} & \\
\hline & & $\mathrm{L}$ & $73.1(2.83)$ & 3.9 & & \\
\hline & \multirow[t]{2}{*}{ Hind } & $\mathrm{H}$ & $63.1(2.63)$ & 4.2 & \multirow[t]{2}{*}{.841} & \\
\hline & & $\mathrm{L}$ & $62.9(2.51)$ & 4.0 & & \\
\hline \multirow{4}{*}{$\begin{array}{l}\text { Vector Magnitude } \\
(\mathrm{N} / \mathrm{kg})\end{array}$} & \multirow[t]{2}{*}{ Fore } & $\mathrm{H}$ & $6.52(0.47)$ & 7.2 & \multirow[t]{2}{*}{.006} & \\
\hline & & $\mathrm{L}$ & $6.35(0.45)$ & 7.1 & & \\
\hline & \multirow[t]{2}{*}{ Hind } & $\mathrm{H}$ & $5.03(0.38)$ & 7.5 & \multirow[t]{2}{*}{.795} & \\
\hline & & $\mathrm{L}$ & $5.05(0.31)$ & 6.2 & & \\
\hline \multirow{4}{*}{$\begin{array}{l}\text { Vector Angle } \\
\text { (degrees) }\end{array}$} & \multirow[t]{2}{*}{ Fore } & $\mathrm{H}$ & $-1.45(0.67)$ & {$[-0.13,-2.36]$} & \multirow[t]{2}{*}{.273} & \\
\hline & & $\mathrm{L}$ & $-1.20(0.28)$ & {$[-0.82,-1.63]$} & & \\
\hline & \multirow[t]{2}{*}{ Hind } & $\mathrm{H}$ & $1.28(0.52)$ & {$[2.02,0.50]$} & \multirow[t]{2}{*}{.718} & \\
\hline & & $\mathrm{L}$ & $1.41(1.08)$ & {$[2.39,-0.77]$} & & \\
\hline
\end{tabular}




\section{Table 4 (on next page)}

Typical force and vector summary variables for the individual horse.

Mean, standard deviation (s.d.) and coefficient of variation (COV) ([range] for VecAng) of typical force variables and vector summary variables for left and right fore and hind limbs for horse 10 trotting in hand, overground. Significant differences between left and right limbs are shaded. Simple bootstrapping was applied to variables denoted with an asterisk*. 


\begin{tabular}{|c|c|c|c|c|c|c|}
\hline Variable & Limb & $\mathrm{L} / \mathrm{R}$ & Mean (s.d.) & $\begin{array}{l}\mathrm{COV}(\%) \\
\text { [Range] }\end{array}$ & $\begin{array}{c}\mathrm{P} \\
\text { value }\end{array}$ & Bootstrap \\
\hline \multirow{4}{*}{$\begin{array}{l}\text { Peak Vertical GRF } \\
(\mathrm{N} / \mathrm{kg})\end{array}$} & \multirow[t]{2}{*}{ Fore } & $\mathrm{L}$ & $10.36(0.18)$ & 1.71 & \multirow{2}{*}{$\begin{array}{c}<.00 \\
1\end{array}$} & \\
\hline & & $\mathrm{R}$ & $10.64(0.22)$ & 2.09 & & \\
\hline & \multirow[t]{2}{*}{ Hind } & $\mathrm{L}$ & $9.21(0.28)$ & 3.07 & \multirow[t]{2}{*}{.012} & \\
\hline & & $\mathrm{R}$ & $9.03(0.20)$ & 2.22 & & \\
\hline \multirow{4}{*}{$\begin{array}{l}\text { Peak Braking GRF } \\
(\mathrm{N} / \mathrm{kg})\end{array}$} & \multirow[t]{2}{*}{ Fore } & $\mathrm{L}$ & $-1.02(0.09)$ & 9.12 & \multirow[t]{2}{*}{.052} & \\
\hline & & $\mathrm{R}$ & $-1.13(0.08)$ & 7.16 & & \\
\hline & \multirow[t]{2}{*}{ Hind } & $\mathrm{L}$ & $-0.73(0.06)$ & 8.00 & \multirow[t]{2}{*}{.374} & \\
\hline & & $\mathrm{R}$ & $-0.76(0.07)$ & 8.72 & & \\
\hline \multirow{4}{*}{$\begin{array}{l}\text { Peak Propulsive GRF } \\
(\mathrm{N} / \mathrm{kg})\end{array}$} & \multirow[t]{2}{*}{ Fore } & $\mathrm{L}$ & $1.04(0.07)$ & 6.40 & \multirow[t]{2}{*}{.051} & \\
\hline & & $\mathrm{R}$ & $0.96(0.09)$ & 9.44 & & \\
\hline & \multirow[t]{2}{*}{ Hind } & $\mathrm{L}$ & $1.12(0.10)$ & 9.16 & \multirow[t]{2}{*}{.008} & * \\
\hline & & $\mathrm{R}$ & $1.00(0.08)$ & 7.47 & & \\
\hline \multirow{4}{*}{$\begin{array}{l}\text { Vertical Impulse } \\
(\mathrm{Ns} / \mathrm{kg})\end{array}$} & \multirow[t]{2}{*}{ Fore } & $\mathrm{L}$ & $2.19(0.03)$ & 1.26 & \multirow[t]{2}{*}{.018} & \\
\hline & & $\mathrm{R}$ & $2.22(0.03)$ & 1.32 & & \\
\hline & \multirow[t]{2}{*}{ Hind } & $\mathrm{L}$ & $1.62(0.05)$ & 1.26 & \multirow[t]{2}{*}{.614} & \\
\hline & & $\mathrm{R}$ & $1.62(0.03)$ & 1.96 & & \\
\hline \multirow{4}{*}{$\begin{array}{l}\text { Braking Impulse } \\
(\mathrm{Ns} / \mathrm{kg})\end{array}$} & \multirow[t]{2}{*}{ Fore } & $\mathrm{L}$ & $-0.13(0.01)$ & 6.44 & \multirow[t]{2}{*}{.024} & \\
\hline & & $\mathrm{R}$ & $-0.14(0.01)$ & 8.43 & & \\
\hline & \multirow[t]{2}{*}{ Hind } & $\mathrm{L}$ & $-0.06(0.01)$ & 17.36 & \multirow[t]{2}{*}{.093} & \\
\hline & & $\mathrm{R}$ & $-0.07(0.01)$ & 14.87 & & \\
\hline \multirow{4}{*}{$\begin{array}{l}\text { Propulsive Impulse } \\
\text { (Ns/kg) }\end{array}$} & \multirow[t]{2}{*}{ Fore } & $\mathrm{L}$ & $0.10(0.01)$ & 9.53 & \multirow[t]{2}{*}{.016} & \\
\hline & & $\mathrm{R}$ & $0.09(0.01)$ & 10.73 & & \\
\hline & \multirow[t]{2}{*}{ Hind } & $\mathrm{L}$ & $0.11(0.01)$ & 11.44 & \multirow[t]{2}{*}{.019} & \\
\hline & & $\mathrm{R}$ & $0.09(0.01)$ & 11.04 & & \\
\hline
\end{tabular}


Manuscript to be reviewed

\begin{tabular}{|c|c|c|c|c|c|c|}
\hline \multirow{4}{*}{$\begin{array}{l}\text { Time to Peak Vertical } \\
\text { GRF (\% stance) }\end{array}$} & \multirow[t]{2}{*}{ Fore } & $\mathrm{L}$ & $44.09(1.25)$ & 2.84 & \multirow[t]{2}{*}{.520} & $*$ \\
\hline & & $\mathrm{R}$ & $44.51(1.66)$ & 3.74 & & \\
\hline & \multirow[t]{2}{*}{ Hind } & $\mathrm{L}$ & $44.24(1.57)$ & 3.54 & \multirow[t]{2}{*}{.164} & $*$ \\
\hline & & $\mathrm{R}$ & $45.88(1.92)$ & 4.18 & & \\
\hline \multirow{4}{*}{$\begin{array}{l}\text { Time to Peak Braking } \\
\text { Force ( } \% \text { stance })\end{array}$} & \multirow[t]{2}{*}{ Fore } & $\mathrm{L}$ & $25.32(2.36)$ & 9.31 & \multirow[t]{2}{*}{.436} & \\
\hline & & $\mathrm{R}$ & $25.98(0.74)$ & 2.87 & & \\
\hline & \multirow[t]{2}{*}{ Hind } & $\mathrm{L}$ & $19.75(1.93)$ & 9.79 & \multirow[t]{2}{*}{.824} & \\
\hline & & $\mathrm{R}$ & $19.98(2.13)$ & 10.64 & & \\
\hline \multirow{4}{*}{$\begin{array}{l}\text { Time to Peak } \\
\text { Propulsive Force ( } \% \\
\text { stance) }\end{array}$} & \multirow[t]{2}{*}{ Fore } & $\mathrm{L}$ & $72.24(1.59)$ & 2.19 & \multirow[t]{2}{*}{.090} & \\
\hline & & $\mathrm{R}$ & $71.19(1.27)$ & 1.78 & & \\
\hline & \multirow[t]{2}{*}{ Hind } & $\mathrm{L}$ & $66.03(2.00)$ & 3.03 & \multirow[t]{2}{*}{.024} & \\
\hline & & $\mathrm{R}$ & $69.40(1.47)$ & 2.12 & & \\
\hline \multirow{4}{*}{$\begin{array}{l}\text { Vector Magnitude } \\
(\mathrm{N} / \mathrm{kg})\end{array}$} & \multirow[t]{2}{*}{ Fore } & $\mathrm{L}$ & $6.10(0.10)$ & 1.67 & \multirow[t]{2}{*}{.001} & \\
\hline & & $\mathrm{R}$ & $6.35(0.16)$ & 2.50 & & $*$ \\
\hline & \multirow[t]{2}{*}{ Hind } & $\mathrm{L}$ & $5.15(0.27)$ & 5.32 & \multirow[t]{2}{*}{.269} & \\
\hline & & $\mathrm{R}$ & $5.08(0.16)$ & 3.15 & & \\
\hline \multirow[t]{4}{*}{ Vector Angle (degrees) } & \multirow[t]{2}{*}{ Fore } & $\mathrm{L}$ & $-0.67(0.48)$ & {$[-0.14,-1.35]$} & \multirow[t]{2}{*}{.016} & \\
\hline & & $\mathrm{R}$ & $-1.47(0.48)$ & {$[-0.89,-2.30]$} & & \\
\hline & \multirow[t]{2}{*}{ Hind } & $\mathrm{L}$ & $1.51(0.74)$ & {$[2.95,0.47]$} & \multirow[t]{2}{*}{.057} & \\
\hline & & $\mathrm{R}$ & $0.67(0.75)$ & {$[1.94,-0.35]$} & & $*$ \\
\hline
\end{tabular}




\section{Table 5 (on next page)}

Relationships between typical force variables and vector summary variables for the group.

Partial correlation matrix between vector metrics and typical force variables for the group of 10 horses (controlling for relative speed). Bootstrapped variables are identified with the following symbol §. Significant relationships are highlighted; $p<.05 *, p<.01 * *$ and shaded. 


\begin{tabular}{|c|c|c|c|c|c|c|c|c|c|c|c|c|c|c|c|c|}
\hline & $\begin{array}{l}\text { Peak } \\
\text { Vertical } \\
\text { GRF F }\end{array}$ & $\begin{array}{l}\text { Peak } \\
\text { Vertical } \\
\text { GRF H }\end{array}$ & $\begin{array}{c}\text { Peak } \\
\text { Braking } \\
\text { GRF F§ }\end{array}$ & $\begin{array}{c}\text { Peak } \\
\text { Braking } \\
\text { GRF H }\end{array}$ & $\begin{array}{c}\text { Peak } \\
\text { Propulsive } \\
\text { GRF F }\end{array}$ & $\begin{array}{c}\text { Peak } \\
\text { Propulsive } \\
\text { GRF H§ }\end{array}$ & $\begin{array}{c}\text { Vertical } \\
\text { Impulse } \\
\text { F }\end{array}$ & $\begin{array}{c}\text { Vertical } \\
\text { Impulse } \\
\mathrm{H} \S\end{array}$ & $\begin{array}{l}\text { Braking } \\
\text { Impulse } \\
\text { F }\end{array}$ & $\begin{array}{c}\text { Braking } \\
\text { Impulse } \\
\mathrm{H}\end{array}$ & $\begin{array}{l}\text { Propulsive } \\
\text { Impulse F }\end{array}$ & $\begin{array}{l}\text { Propulsive } \\
\text { Impulse H }\end{array}$ & $\begin{array}{c}\text { Vec } \\
\text { Mag F }\end{array}$ & $\begin{array}{c}\text { Vec } \\
\text { Mag H }\end{array}$ & $\begin{array}{l}\text { Vec } \\
\text { Ang F }\end{array}$ & $\begin{array}{c}\text { Vec } \\
\text { Ang H }\end{array}$ \\
\hline $\begin{array}{l}\text { Peak Vertical } \\
\text { GRF F }\end{array}$ & 1.000 & & & & & & & & & & & & & & & \\
\hline $\begin{array}{c}\text { Peak Vertical } \\
\text { GRF H }\end{array}$ & $.637 * *$ & 1.000 & & & & & & & & & & & & & & \\
\hline $\begin{array}{c}\text { Peak Braking } \\
\text { GRF F§ }\end{array}$ & $-.691 * *$ & -.352 & 1.000 & & & & & & & & & & & & & \\
\hline $\begin{array}{c}\text { Peak Braking } \\
\text { GRF H }\end{array}$ & .135 & -.063 & -.161 & 1.000 & & & & & & & & & & & & \\
\hline $\begin{array}{c}\text { Peak } \\
\text { Propulsive } \\
\text { GRF F }\end{array}$ & .364 & .319 & -.128 & -.418 & 1.000 & & & & & & & & & & & \\
\hline $\begin{array}{c}\text { Peak } \\
\text { Propulsive } \\
\text { GRF H§̧ }\end{array}$ & .061 & .199 & .326 & .037 & .416 & 1.000 & & & & & & & & & & \\
\hline $\begin{array}{l}\text { Vertical } \\
\text { Impulse } \mathrm{F}\end{array}$ & $.741 * *$ & $.535^{*}$ & $-.637 * *$ & -.121 & $.699 * *$ & .150 & 1.000 & & & & & & & & & \\
\hline $\begin{array}{l}\text { Vertical } \\
\text { Impulse H§ }\end{array}$ & .326 & $.465^{*}$ & -.130 & -.338 & $.640 * *$ & .317 & $.663 * *$ & 1.000 & & & & & & & & \\
\hline $\begin{array}{l}\text { Braking } \\
\text { Impulse } \mathrm{F}\end{array}$ & $-.670 * *$ & -.408 & $.924 * *$ & -.037 & -.207 & .241 & $-.737 * *$ & -.324 & 1.000 & & & & & & & \\
\hline $\begin{array}{l}\text { Braking } \\
\text { Impulse } \mathrm{H}\end{array}$ & .120 & .093 & -.111 & $.929 * *$ & .442 & .012 & -.226 & -.445 & .030 & 1.000 & & & & & & \\
\hline $\begin{array}{l}\text { Propulsive } \\
\text { Impulse F }\end{array}$ & .218 & .204 & -.091 & $-.466^{*}$ & $.959 * *$ & .347 & $.688 * *$ & $.630^{* *}$ & -.180 & $-.530 *$ & 1.000 & & & & & \\
\hline $\begin{array}{l}\text { Propulsive } \\
\text { Impulse H }\end{array}$ & .386 & .368 & -.183 & .223 & .467 & .319 & $.505^{*}$ & $.733 * *$ & -.290 & .144 & .404 & 1.000 & & & & \\
\hline VecMag F & $.939 * *$ & $.764^{* *}$ & $-.738^{* *}$ & .114 & .387 & .041 & $.792 * *$ & .370 & $-.739 * *$ & .120 & .265 & .372 & 1.000 & & & \\
\hline VecMag H & $.758 * *$ & $.905^{* *}$ & $-.577 * *$ & .205 & .221 & .104 & $.674 * *$ & .421 & $-.613^{* *}$ & .253 & .146 & .436 & $.868 * *$ & 1.000 & & \\
\hline VecAng F & -.317 & -.142 & $.632^{* *}$ & -.406 & $.615^{* *}$ & $.468^{*}$ & .001 & .276 & $.610^{* *}$ & -.412 & $.665^{* *}$ & .111 & -.338 & -.348 & 1.000 & \\
\hline VecAng $\mathrm{H}$ & .311 & .244 & -.183 & $.812 * *$ & -.022 & .202 & .133 & .110 & -.138 & $.800 * *$ & -.128 & $.701 * *$ & .299 & .406 & -.210 & 1.000 \\
\hline
\end{tabular}




\section{Figure 1}

Force vector diagram for a forelimb of a horse trotting overground.

Sagittal plane force vectors (dark red lines) are constructed at intervals of $0.0083 \mathrm{~s}$. Each vector originates at its centre of pressure, which is identified relative to the hoof location on the force plate. The length is proportional in magnitude to that of the force and it is oriented in the direction of the force. The vector envelope joins the peripheral tips of the force vectors. The black vertical line is drawn through the dorsopalmar midpoint of the hoof. The summary vector is shown as a heavy red line originating at the midpoint of the hoof; its length represents the mean magnitude (VecMag) and its angle to the vertical represents the mean angle (VecAng) of all vectors throughout the stance phase. 


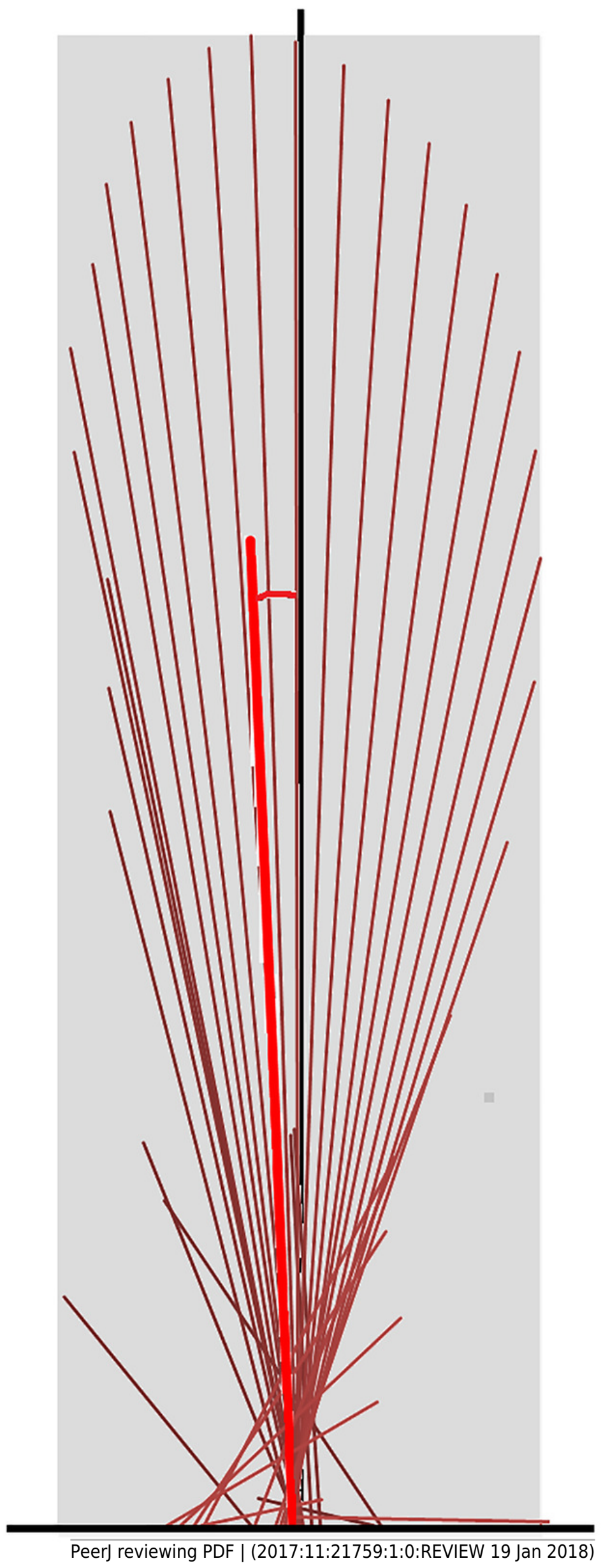




\section{Figure 2}

Stick figures, time-normalized vertical and longitudinal ground reaction forces and vector diagrams for the two diagonals of one consecutive stride from horse trotting overground.

A) Sequential stick figures of the horse at $10 \%$ intervals of the stride. B) Vertical ground reaction forces $(\mathrm{N} / \mathrm{kg})$ for the fore and hind limbs of each diagonal pair. C) Longitudinal ground reaction forces $(\mathrm{N} / \mathrm{kg})$ for the fore and hind limbs of each diagonal pair. D) Vector diagrams constructed from the force data in B and $C$ showing summary vectors for each limb (summary vectors shown in black). Blue: left forelimb; red: right forelimb; orange: right hind limb; green: left hind limb. RH: right hind; LF: left fore; LH: left hind; RF: right fore; LFRH: left fore and right hind diagonal; RFLH: right fore and left hind diagonal.
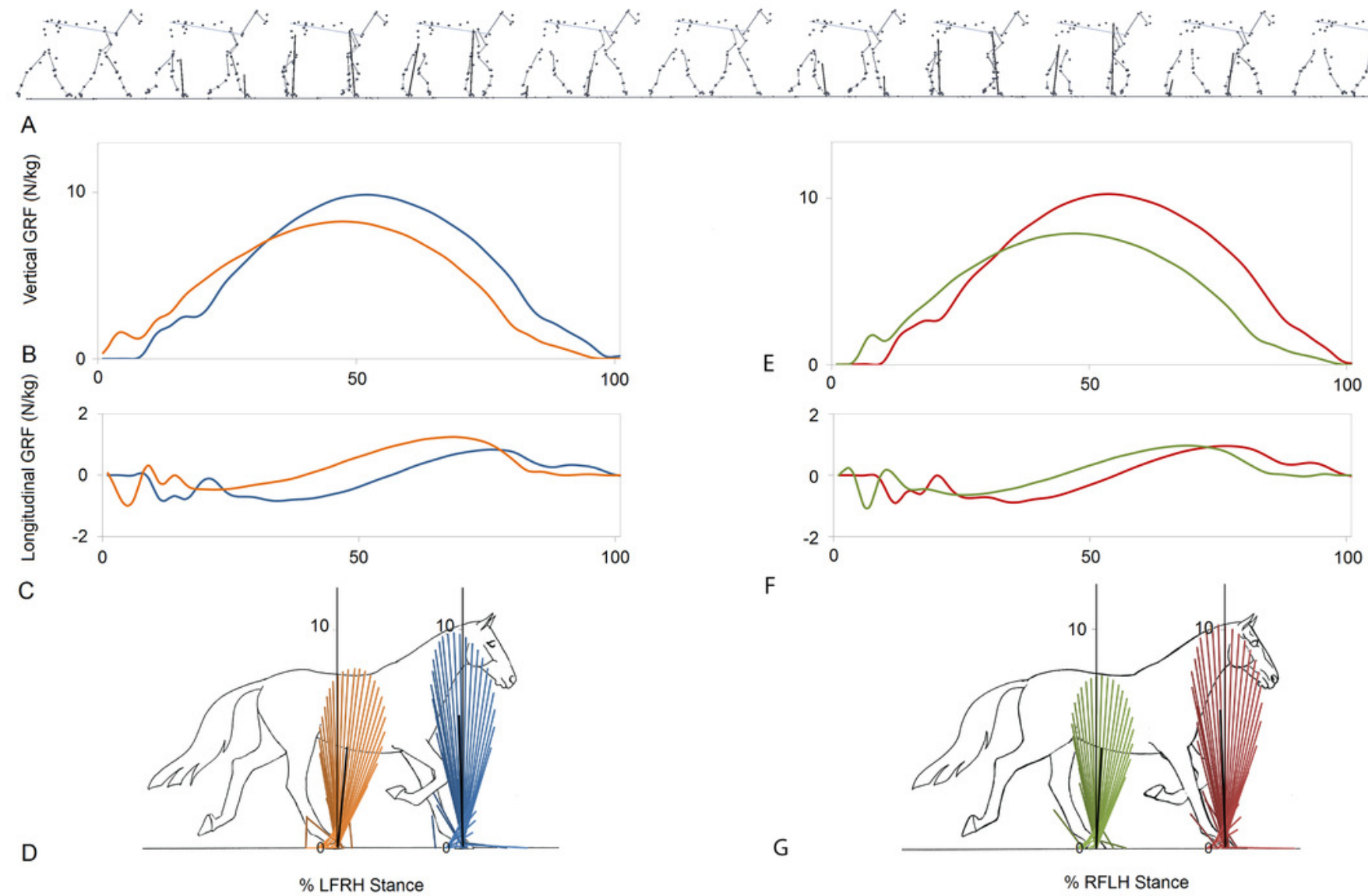

$\mathrm{F}$

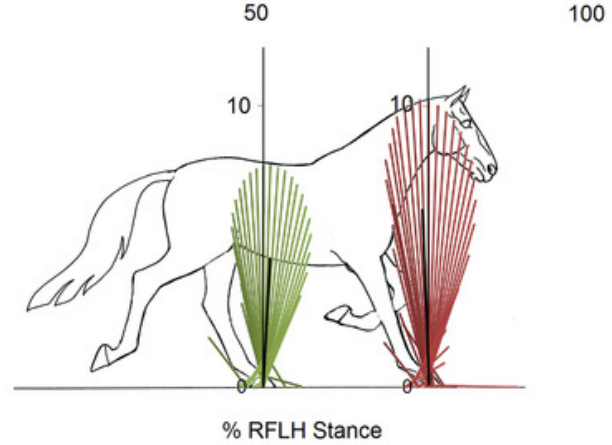




\section{Figure 3}

Results of statistical parametric mapping of ground reaction forces at trot overground for a group of 10 horses comparing left limb against right limb (mean of 3 stance phases per horse, per limb).

A) The Hotelling's $T^{2}$ test results (vertical and longitudinal ground reaction forces combined), the $T^{2}$ statistic (black line) did not exceed the critical threshold (red dashed line) therefore there were no statistical differences. B) mean (solid line) and standard deviation (shaded area) vertical and C) mean (solid line) and standard deviation (shaded area) longitudinal ground reaction forces for the group $(\mathrm{N} / \mathrm{kg})$. Blue: left forelimb; red: right forelimb; orange: right hind limb; green: left hind limb. 
Fore
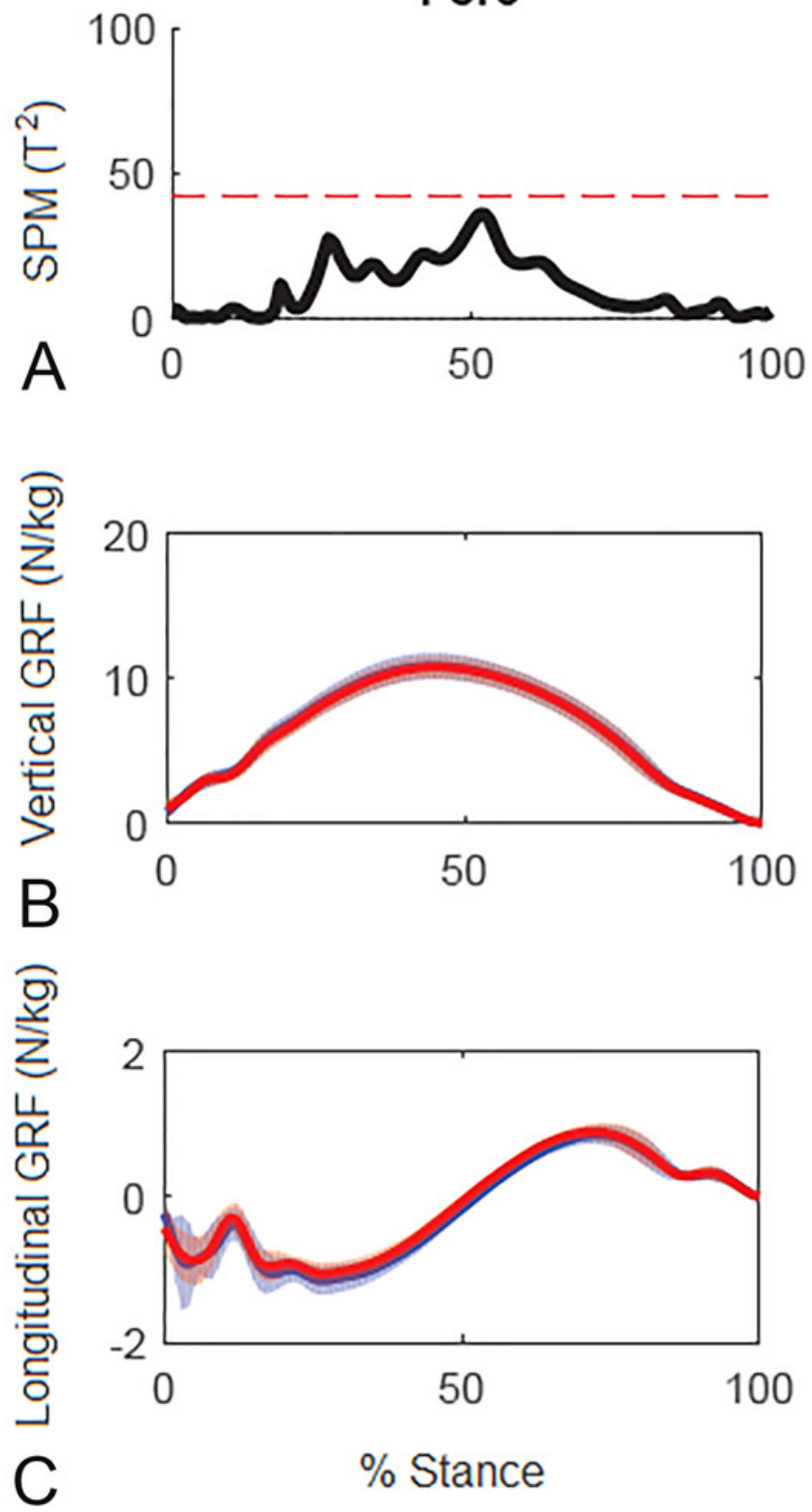

Hind
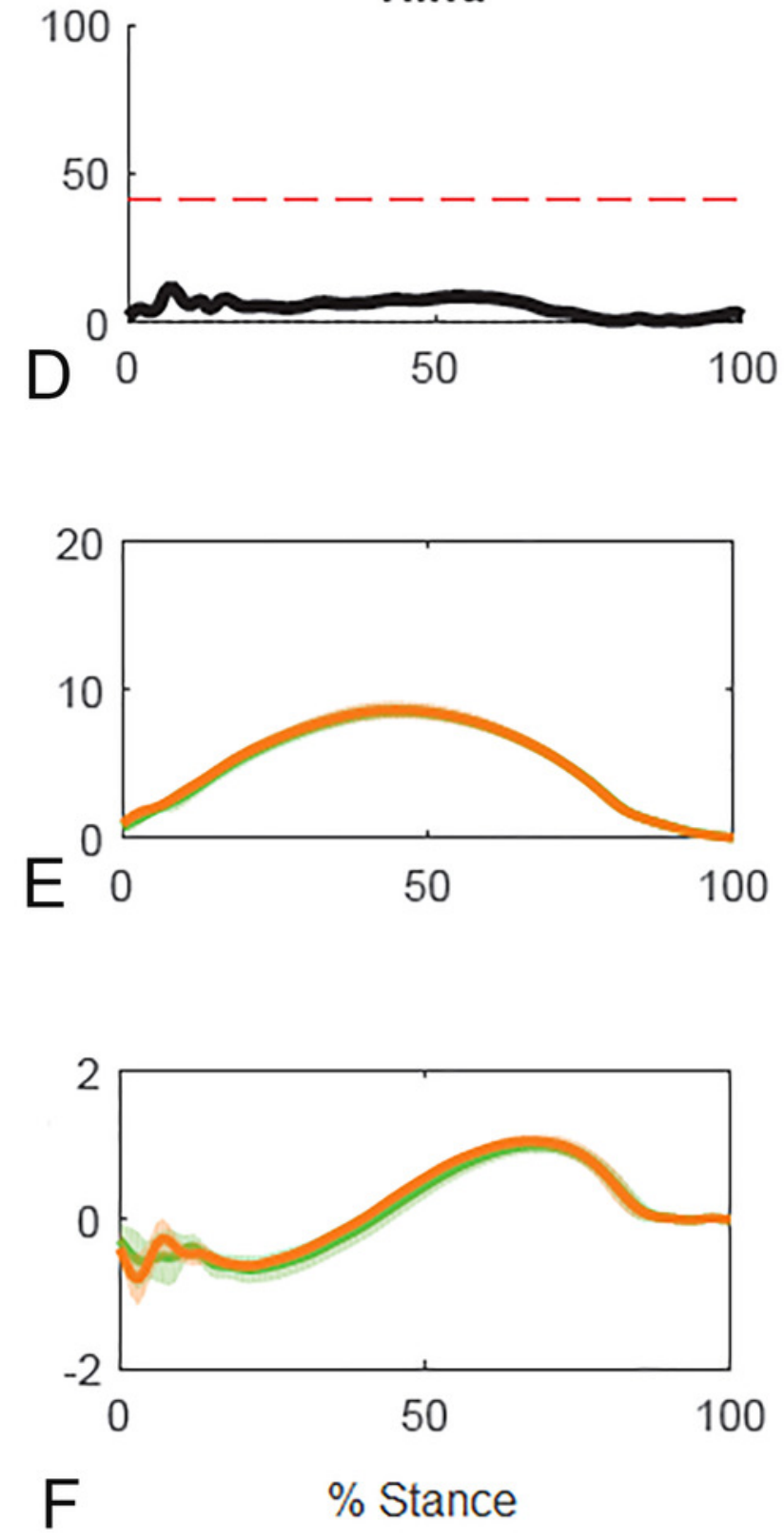


\section{Figure 4}

Results of statistical parametric mapping of ground reaction forces of trot overground for a group of 10 horses categorized by forelimb vertical GRF (mean of 3 stance phases per horse, per limb).

A) The Hotelling's $T^{2}$ test SPM results (vertical and longitudinal ground reaction forces combined), the $T^{2}$ statistic did not exceed the critical threshold (red dashed line) therefore there were no statistical differences. B) mean (solid line) and standard deviation (shaded area) vertical and C) mean (solid line) and standard deviation (shaded area) longitudinal ground reaction forces for the group (N/kg). Red: forelimb with higher peak vertical GRF; Blue: forelimb with lower peak vertical GRF; orange: diagonal hind limb of the forelimb with higher peak vertical GRF; green: diagonal hind limb of the forelimb with lower peak vertical GRF. 
Fore
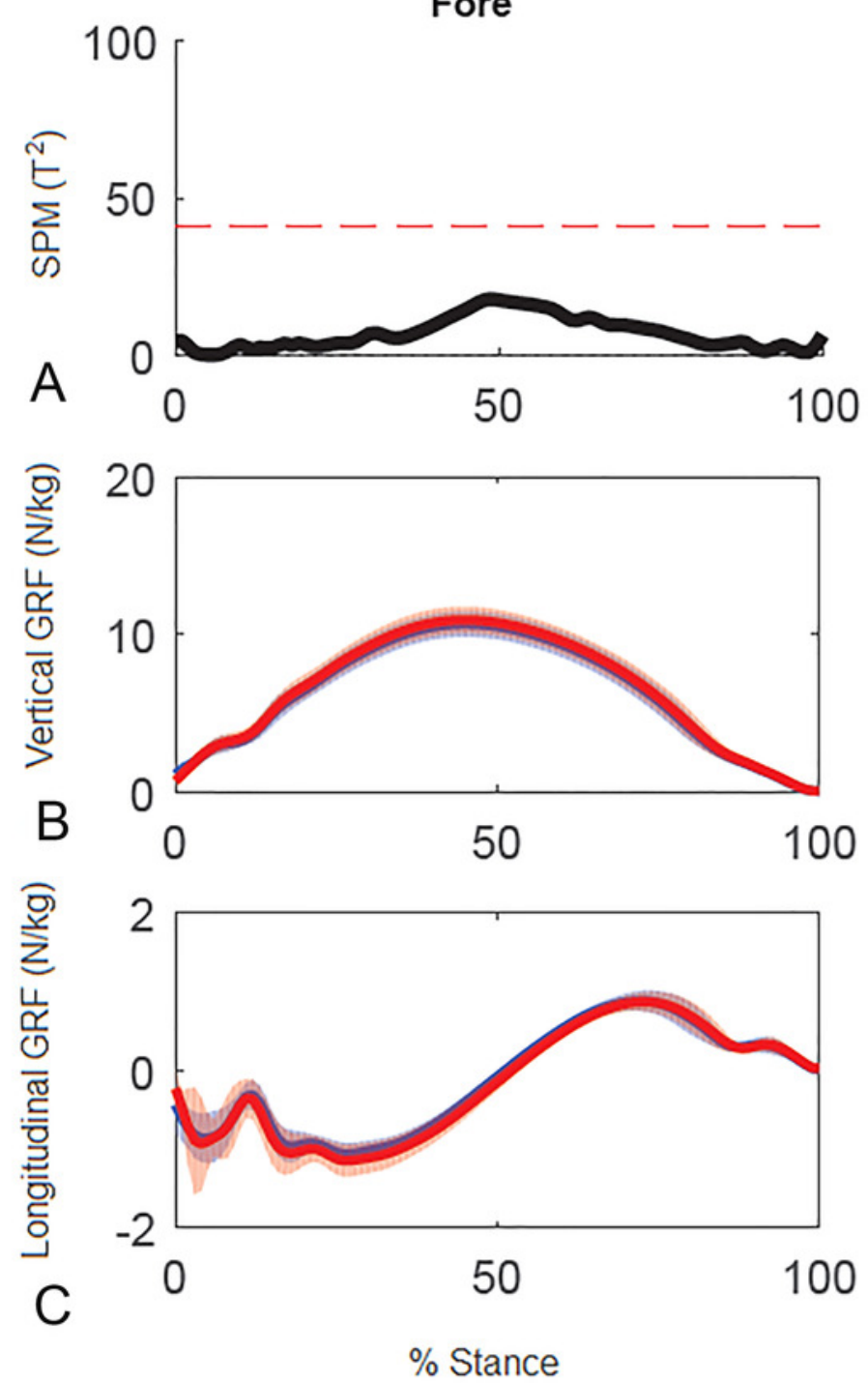

Hind

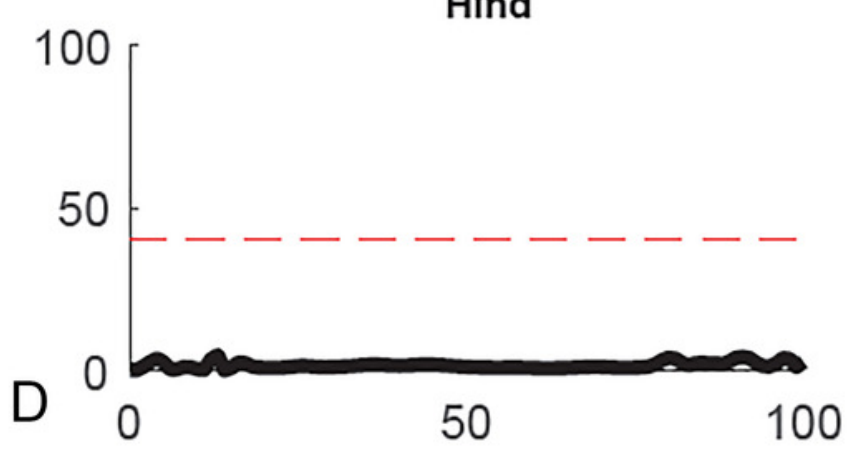

E
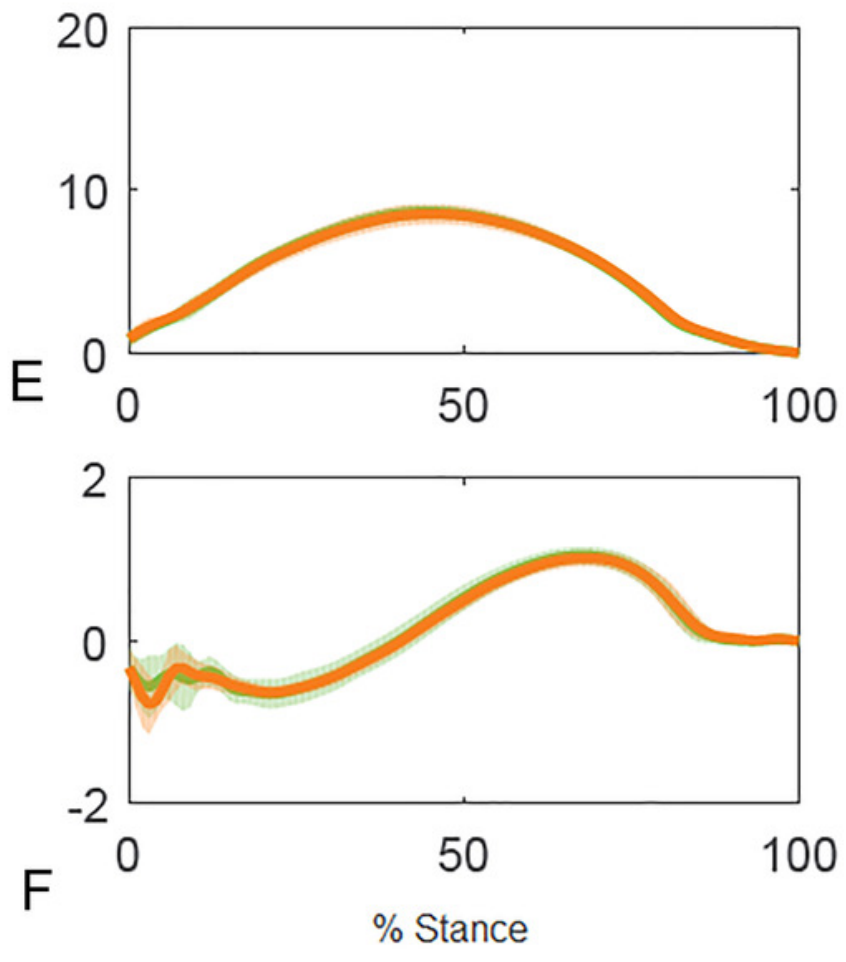


\section{Figure 5}

Results of statistical parametric mapping of ground reaction forces of trot overground for one horse (8 stance phases per limb).

A) The Hotelling's $T^{2}$ test SPM results (vertical and longitudinal ground reaction forces combined), the $T^{2}$ statistic crossed the critical threshold in three regions indicating that there was a significant differences in the forelimbs, B) mean (solid line) and standard deviation (shaded area) vertical ground reaction forces $(\mathrm{N} / \mathrm{kg}), \mathrm{C}$ ) post-hoc paired-samples SPM( $\mathrm{t}$ ) results for the vertical force component, D) mean (solid line) and standard deviation (shaded area) longitudinal ground reaction forces ( $\mathrm{N} / \mathrm{kg})$, and $\mathrm{E}$ ) post-hoc paired-samples SPM(t) results for the longitudinal force component for horse 10 Blue: left forelimb; red: right forelimb; orange: right hind limb; green: left hind limb. 
Fore
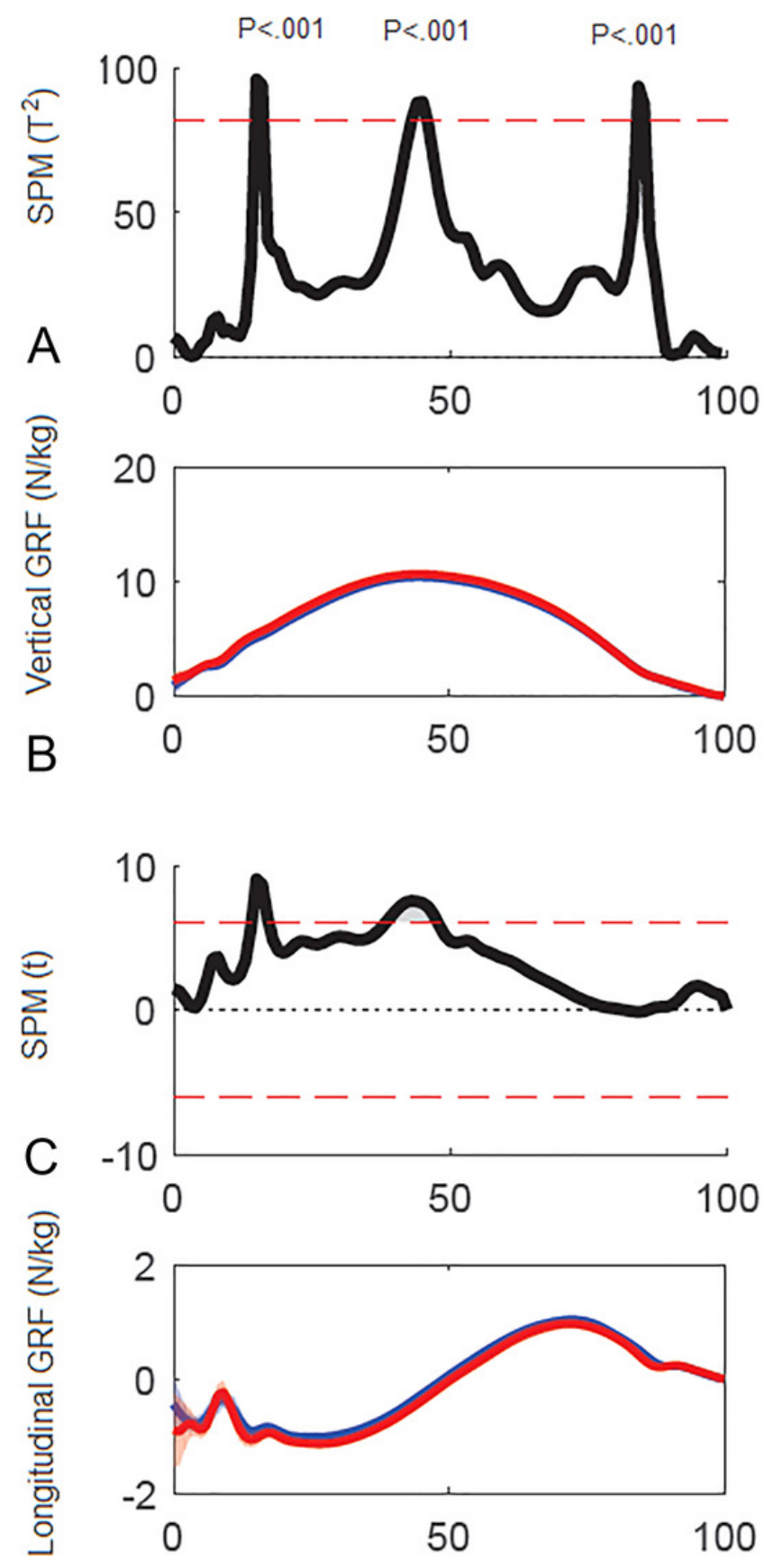

D

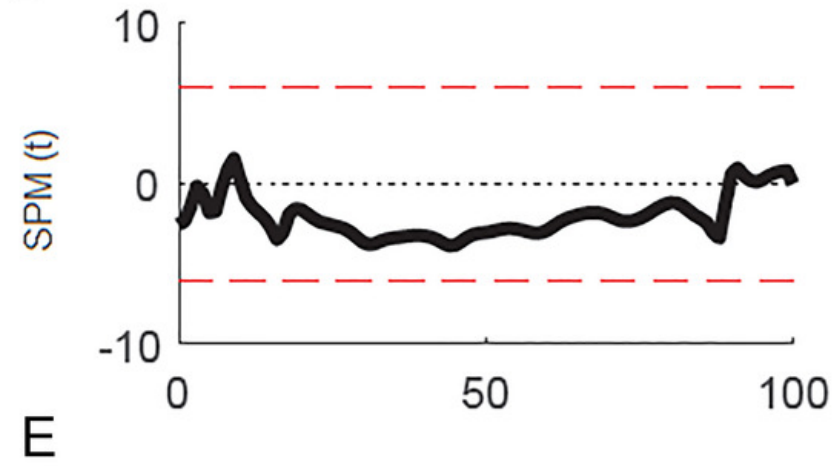

Hind
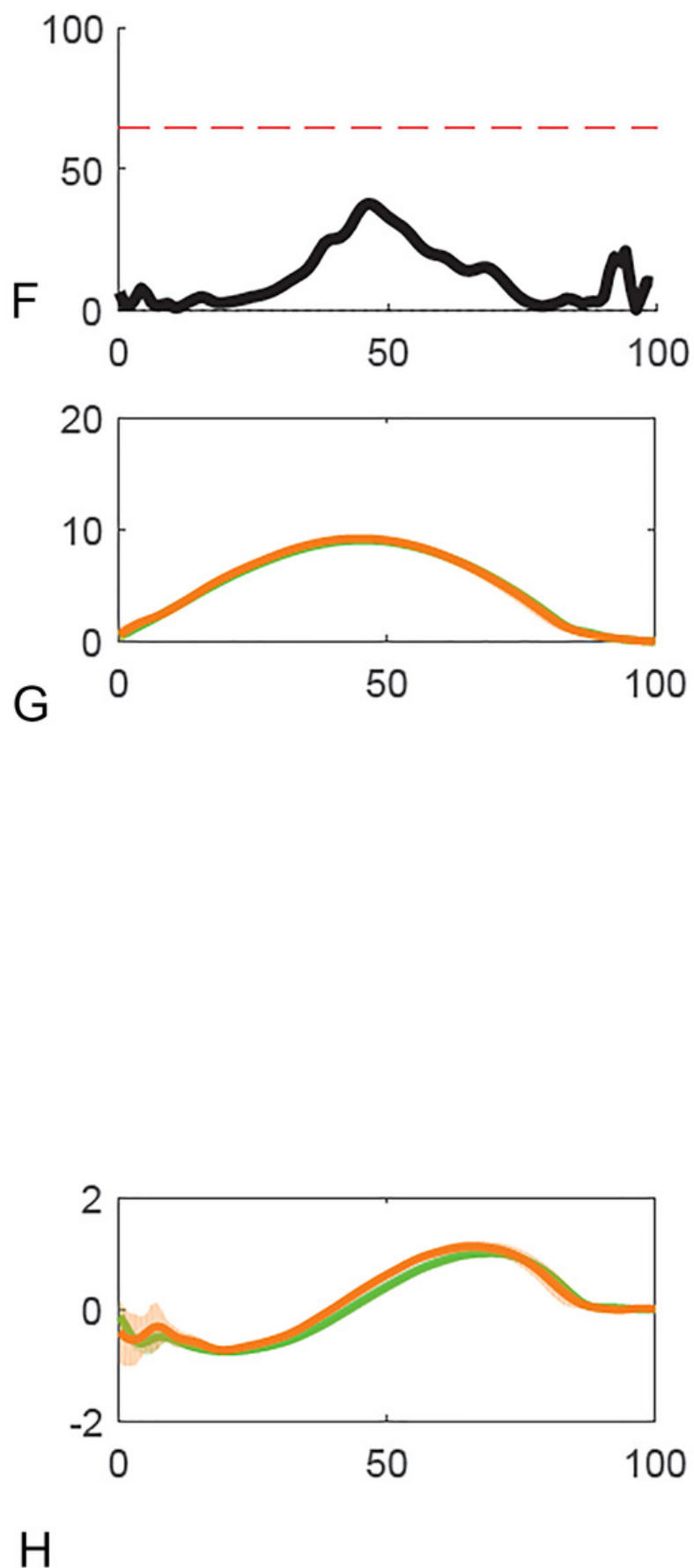

$\mathrm{H}$ 
Figure 6

Force vector diagrams overlaid for contralateral limbs of horse 10 trotting overground.

RH: right hind; LF: left fore; LH: left hind; RF: right fore.

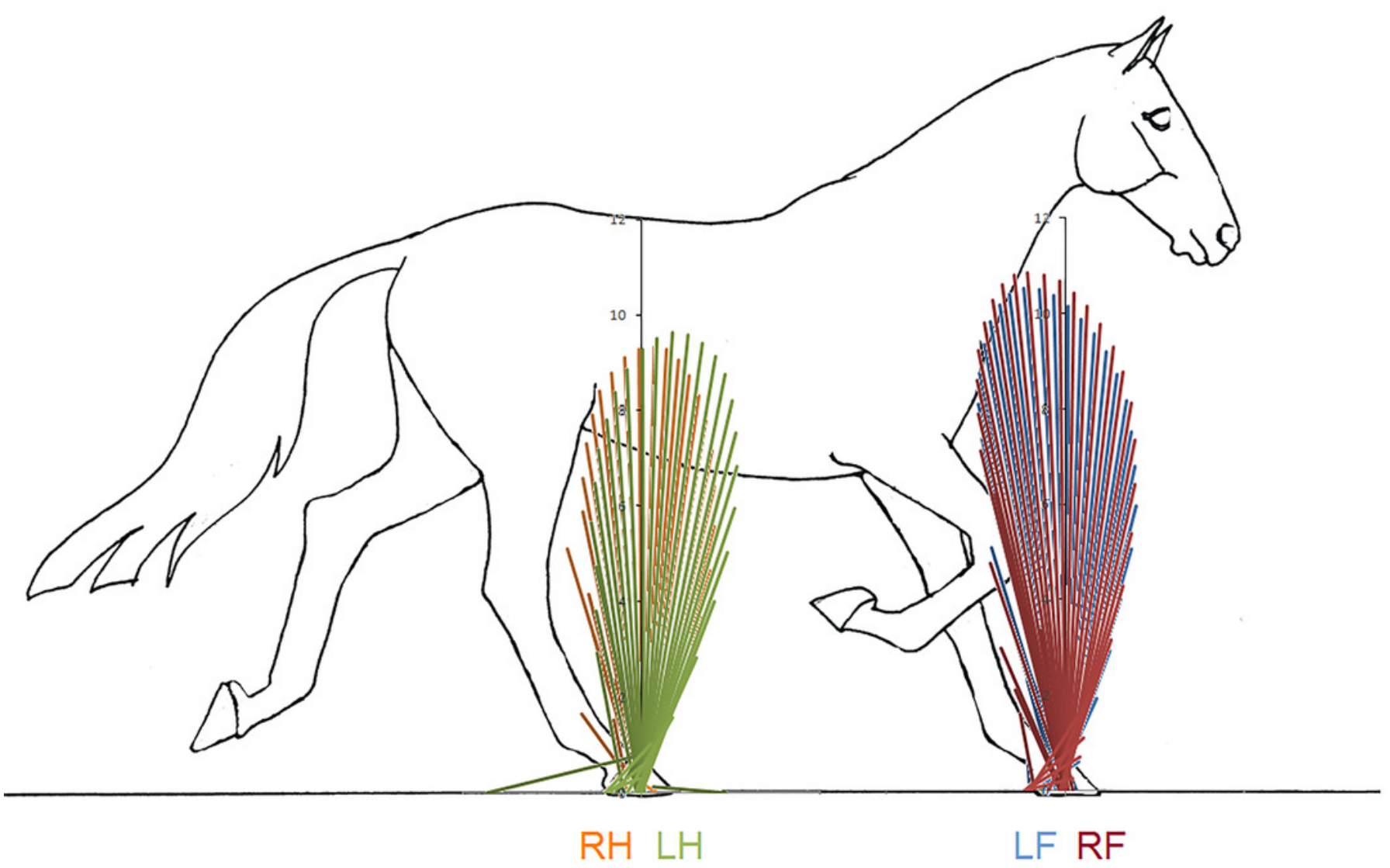

